NBER WORKING PAPER SERIES

\title{
THE POSITIVE LINK BETWEEN FINANCIAL LIBERALIZATION GROWTH AND CRISES
}

\author{
Aaron Tornell \\ Frank Westermann \\ Lorenza Martinez \\ Working Paper 10293 \\ http://www.nber.org/papers/w10293 \\ NATIONAL BUREAU OF ECONOMIC RESEARCH \\ 1050 Massachusetts Avenue \\ Cambridge, MA 02138 \\ February 2004
}

This paper is part of "Liberalization, Growth and Financial Crises: Lessons from Mexico and the Developing World" that was prepared for the Brookings Panel on Economic Activity. We want to thank Pedro Aspe, Sasha Becker, Bill Brainard, Pierre O. Gourinchas, Gordon Hanson, Graciela Kaminski, Tim Kehoe, Aart Kraay, Anne Krueger, Norman Loayza, George Perry, Romain Ranciere, Luis Serven, Sergio Schmuckler, Carolyn Sissoko and Alejandro Werner for helpful discussions. The views expressed herein are those of the authors and not necessarily those of the National Bureau of Economic Research.

(C2004 by Aaron Tornell, Frank Westermann, and Lorenza Martinez. All rights reserved. Short sections of text, not to exceed two paragraphs, may be quoted without explicit permission provided that full credit, including (C) notice, is given to the source. 
The Positive Link Between Financial Liberalization, Growth and Crises Aaron Tornell, Frank Westermann, and Lorenza Martinez

NBER Working Paper No. 10293

February 2004

JEL No. E20, E44, F30, F43, G15 O40, O50

\begin{abstract}
There is no agreement regarding the growth-enhancing effects of financial liberalization, mainly because it is associated with risky international bank flows, lending booms, and crises. In this paper we make the case for liberalization despite the occurrence of crises. We show that in developing countries trade liberalization has typically been followed by financial liberalization, which has indeed led to financial fragility and a greater incidence of crises. However, financial liberalization also has led to higher GDP growth. In fact, the fastest-growing countries are typically those that have experienced boom-bust cycles. That is, there is a positive link between GDP growth and the bumpiness of credit, which is captured by the negative skewness --not by the variance-- of credit growth. To substantiate our interpretation of the data we present a model that shows why in countries with severe credit market imperfections, liberalization leads to higher growth and, as a byproduct, to financial fragility. Thus, occasional crises need not forestall growth and may even be a necessary component of a developing country's growth experience. Finally, our analysis indicates that foreign direct investment does not obviate the need for risky international bank flows, as the latter are the only source of financing for most firms in the nontradables sector.

Aaron Tornell

Department of Economics

UCLA

405 Hilgard Ave, Bunche Hall \#8283

Los Angeles, CA 90095-1477

and NBER

tornell@ucla.edu

Frank Westermann

CESifo (University of Munich and ifo Institut) Shackstr. 4

80539 Munich, Germany

frank.westermann@ces.vwl.uni-muenchen.de

Lorenza Martinez

Banco de Mexico

lmartin@banxico.org.mx
\end{abstract}




\section{Introduction}

By now there is widespread agreement that trade liberalization enhances growth. No such agreement exists, however, on the growth-enhancing effects of financial liberalization, in large part because it is associated with risky capital flows, lending booms, and crises.

That financial liberalization is bad for growth because it leads to crises is the wrong lesson to draw. Our empirical analysis shows that, in countries with severe credit market imperfections, financial liberalization leads to more rapid growth, but also to a higher incidence of crises. In fact, most of the fastest-growing countries of the developing world have experienced boom-bust cycles. We argue that liberalization leads to faster growth because it eases financial constraints, but that this occurs only if agents take on credit risk, which makes the economy fragile and prone to crisis. An implication of our analysis is that the international bank flows that follow financial liberalization and increase financial fragility are an important component of a rapid-growth path. Foreign direct investment is not a substitute for risky bank flows.

We also find that asymmetries between the tradables $(\mathrm{T})$ and nontradables $(\mathrm{N})$ sectors are key to understanding the links among liberalization and growth, as well as the boom-bust cycles typically experienced by liberalized developing countries.

To substantiate our interpretation of the data, we present a model that establishes a causal link from liberalization to growth, and in which the same forces that lead to faster growth also generate financial fragility. The model leads us to divide our data set into countries with high and intermediate degrees of contract enforceability (which we call high-enforceability and medium-enforceability countries, or HECs and MECs, respectively).

Our data analysis shows that, across MECs, trade liberalization has typically been followed by financial liberalization, which has led to financial fragility and to occasional crises. On average, however, both trade and financial liberalization have led to more rapid long-run growth in GDP per capita across the set of countries with active financial markets. Furthermore, we find that this positive link is not generated by a few fast-growing countries that experienced no crisis. Instead, it is typically the fastest-growing countries that have experienced crises. This suggests that the same mechanism that links liberalization with growth in MECs also generates, as a by-product, financial fragility and occasional crises.

These facts do not contradict the negative link between growth and the variance of several macroeconomic variables - the typical measure of volatility in the literature. A high variance reflects not only the uneven progress, or "bumpiness," associated with occasional crises, but also high-frequency shocks. Instead we measure the incidence of occasional crises by the (negative) skewness of real credit growth. Our findings show that fast-growing MECs tend to have negatively skewed credit growth paths. 
Our explanation for the links among liberalization, bumpiness, and growth is based on the fact that many developing countries have severe contract enforceability problems. Because liberalization has not been accompanied by judicial reform, these problems have persisted. The key point is that these problems affect firms asymmetrically: whereas many T-sector firms can overcome these problems by accessing international capital markets, most $\mathrm{N}$-sector firms cannot. Thus $\mathrm{N}$-sector firms are financially constrained and depend on domestic bank credit.

Trade liberalization increases GDP growth by promoting T-sector productivity. Financial liberalization adds even more to GDP growth by accelerating financial deepening and thus increasing the investment of financially constrained firms, most of which are in the N-sector. However, the easing of financial constraints is associated with the undertaking of credit risk, which often takes the form of foreign currency-denominated debt backed by $\mathrm{N}$-sector output. Credit risk arises because financial liberalization not only lifts restrictions that preclude risk taking, but also is associated with explicit and implicit systemic bailout guarantees that cover creditors against systemic crises. ${ }^{1}$ Not surprisingly, an important share of capital inflows takes the form of risky bank flows, and the economy as a whole experiences aggregate fragility and occasional crises.

Rapid N-sector growth helps the T-sector grow faster by providing abundant and cheap inputs. Thus, as long as a crisis does not occur, growth in a risky economy is more rapid than in a safe one. Of course, financial fragility implies that a self-fulfilling crisis may occur. And, during a crisis, GDP growth falls and typically turns negative. Crises must be rare, however, in order to occur in equilibriumotherwise agents would not find it profitable to take on credit risk in the first place. Thus average long-run growth may be faster along a risky path than along a safe one. Our model follows this intuition to establish a causal link from liberalization to GDP growth. This link is independent of the nominal exchange rate regime.

The argument imposes restrictions on the behavior of credit and of the N-to-T output ratio that help us identify the mechanism. First, credit growth and the N-to-T output ratio should fall drastically in the wake of crisis, and because crises are infrequent, they should exhibit a negatively skewed distribution. Second, during normal times the N-to-T output ratio should vary with credit. Finally, the N-to-T output ratio should decrease following trade liberalization and increase following financial liberalization. We show that the bumpiness of credit growth and these asymmetric sectoral responses are indeed an empirical regularity across MECs. We are not aware of other theoretical arguments that relate the N-to-T output ratio to liberalization, growth, and crises and that explains the empirical regularities we have found.

\footnotetext{
${ }^{1}$ We distinguish two types of bailout guarantees: unconditional and systemic. The former are granted whenever an individual borrower defaults, whereas the latter are granted only if a critical mass of borrowers default. Throughout this paper we focus on systemic guarantees.
} 
Consider next the question of the structure of capital flows. Although several observers have advocated limiting bank flows and promoting FDI as a way to reduce financial fragility, our framework makes it clear that limiting bank flows may hinder growth. We document that the lion's share of FDI goes to the T-sector or to financial institutions and, moreover, that the small share that goes to the N-sector is allocated to very large firms. Thus most of the inflows that end up in the N-sector are intermediated by domestic banks. In countries with severe contract enforcement problems, a policy that limits bank flows constrains the $\mathrm{N}$-sector at best, and at worst prevents it from growing for years. Thus FDI is not a substitute for risky bank flows.

The findings of this paper do not imply that crises are a good thing. They are the price that must be paid to attain rapid growth in the presence of contract enforceability problems. The first-best policy is to improve domestic credit markets by implementing judicial reform. If this is not feasible, liberalization will likely lead to financial fragility, as risky bank flows become the only source of finance for a large group of firms. Such flows are necessary to avoid bottlenecks and ensure long-run growth.

The link between liberalization and growth has generated controversy, because some researchers have found no significant positive link between the two. This finding might be due either to the country sample being considered or to the use of openness indicators. The model we present shows that the asymmetric sectoral responses and the links among liberalization, bumpiness, and growth arise only if contract enforceability problems are severe without being too severe. This underlies the importance of the country sample one considers and leads us to focus on the set of countries with functioning financial markets. In order to analyze the effects of liberalization, we construct de facto indexes of trade and financial liberalization that distinguish the year of liberalization. This allows us to compare the behavior of several macroeconomic variables in both closed and open country-years.

The paper is structured as follows. The next two sections analyze the links among liberalization, bumpiness, and growth. Section 4 analyzes the structure of capital flows. Section 5 presents some economic policy lessons and concludes. Appendixes to the paper describe the model and the construction of our variables. 


\section{The Effects of Liberalization}

In this section we analyze empirically the links among liberalization, financial fragility, and growth across the set of countries with functioning financial markets. The mechanism described in the introduction operates only in countries with a basic level of contract enforcement that permits agents to attain high enough leverage and reap the benefits of liberalization. Thus we restrict our data set to countries where the ratio of stock market turnover to GDP was greater than 1 percent in 1998. This set consists of sixty-six countries, fifty-two of which have data available for the period 1980-99. Throughout the paper we partition this set into seventeen HECs and thirty-five MECs. The former group includes the Group of Seven large industrial countries and those countries in which the rule of law index of Kaufman and Aart Kraay is greater than $1.4 .^{2}$

To assess the effects of liberalization we analyze several macroeconomic variables before and after dates of liberalization. To do this, we construct two de facto indexes that signal the year during which an MEC switches from closed to open. The trade liberalization index signals that a country is open if its ratio of trade (exports plus imports) to GDP exhibits a trend break or is greater than 30 percent. The financial liberalization index signals an opening when the series of cumulative capital inflows experiences a trend break or if they exceed 10 percent of GDP. The idea is that a large change in a measure of openness indicates that a policy reform has taken place and that the reform has had a significant effect on actual flows.

As explained in more detail in appendix B, we identify the breakpoints using the cumulative sum of residuals (CUSUM) method. In most cases the opening dates identified by our indexes are similar to those identified by the stock market liberalization index of G. Bekaert, C. Harvey, and R. Lundblad, the financial liberalization index of Graciela Kaminski and Sergio Schmukler, and the trade liberalization index of Jeffrey Sachs and Andrew Warner. ${ }^{3}$

\footnotetext{
${ }^{2}$ Kaufman and Kraay (1998). The HECs are Australia, Austria, Canada, Denmark, Finland, France, Germany, Italy, Japan, Luxembourg, the Netherlands, New Zealand, Norway, Sweden, Switzerland, the United Kingdom, and the United States. The MECs are Argentina, Bangladesh, Belgium, Brazil, Chile, China, Colombia, Ecuador, Egypt, Greece, Hong Kong, Hungary, India, Indonesia, Ireland, Israel, Jordan, Korea, Malaysia, Mexico, Morocco, Pakistan, Peru, Philippines, Poland, Portugal, South Africa, Spain, Sri Lanka, Thailand, Tunisia, Turkey, Uruguay, Venezuela, and Zimbabwe. The sample includes forty-one of the forty-four countries in the International Finance Corporation's emerging markets database, the exceptions being Costa Rica, Jamaica, and Singapore. Of these, the first two do not satisfy the 1 percent stock market turnover criterion, and for Singapore we do not have data.

${ }^{3}$ Bekaert, Harvey, and Lundblad (2001); Kaminski and Schmukler (2002); Sachs and Warner (1995). Bekaert, Harvey, and Lundblad focus on stock market liberalization, which, although highly correlated with, is distinct from financial or capital account liberalization. Listed firms are a privileged set. Stock market liberalization gives them even more opportunities but does not by itself relax the credit constraints on all other firms. Our argument is that financial liberalization promotes growth because it eases the borrowing constraints faced by the latter set of firms. Kaminski and Schmukler's (2002) index of financial liberalization covers only a small subset of countries.
} 
The country-years identified as liberalized by our indexes do not always coincide with good economic times, during which capital is flowing in and the economy is booming. Liberalized countryyears include both boom and bust episodes.

All the HECs in our sample have been open since 1980, which is the beginning of our sample period. Figure 1 exhibits the shares of MECs in our sample that have become open to trade and financial flows. It shows that in 1980 only 25 percent of these countries were open to trade. Most of these countries started to liberalize in the mid-1980s, and 84 percent had liberalized their trade by 1999.

\section{Figure 1: Share of Countries that Liberalized Trade and Financial Flows}

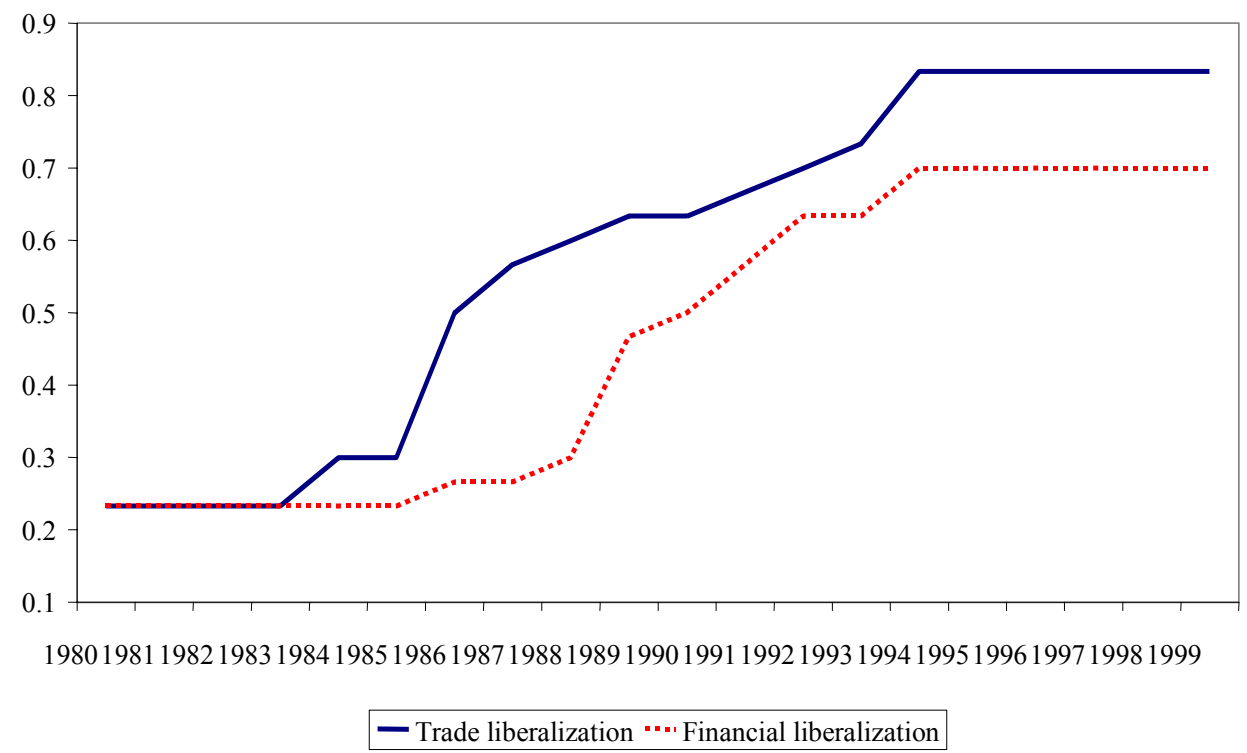

Note: The figure shows the share of countries that have liberalized relative to the total number of MECs in our sample. Source: own calculations.

Several observers have suggested that, to avoid volatility, countries should liberalize trade but not financial flows. Our first stylized fact indicates that this has typically not occurred.

Stylized fact 1. Over the last two decades trade liberalization has typically been followed by financial liberalization.

Our indexes show that, by 1999, 72 percent of countries that had liberalized trade had also liberalized financial flows, bringing the share of MECs that are financially liberalized from 25 percent in 1980 to 69 percent. This close association suggests that an open trade regime is usually sustained with an open financial regime, because exporters and importers need access to international financial markets. Since capital is fungible, it is difficult to insulate the financial flows associated with trade transactions. A 
few exceptions such as India, Sri Lanka, and Venezuela have liberalized trade but have not liberalized their financial markets.

The hypothesis that trade liberalization leads to financial liberalization can be tested with Granger causality tests. The null hypothesis that trade liberalization does not lead to financial liberalization is rejected, with an $F$ statistic of 3.671, which corresponds to a $p$ value of 0.05 . By contrast, the null hypothesis that financial liberalization does not lead to trade liberalization cannot be rejected, with an $F$ statistic of only 0.018 , which corresponds to a $\mathrm{p}$ value of 0.98 .

\section{Liberalization and GDP Growth}

Here we show that, across the set of countries with functioning financial markets, both trade and financial liberalization have been, on average, good for growth. This result confirms similar links established in the literature. In the next two subsections we address the point, made by several observers, that liberalization might not be growth enhancing because it leads to crises. We will show that, indeed, financial liberalization has typically been followed by booms and busts, but also that financial fragility has been associated with faster GDP growth in spite of the fact that it leads to crises.

In this section we will not say anything about causality. Appendix A presents a model that shows that, in the presence of credit market imperfections, liberalization leads to faster growth because it allows financially constrained firms to undertake credit risk, which both eases borrowing constraints and generates financial fragility, leading to occasional crises. The model establishes a causal link from liberalization to growth and has testable implications, which we will use to identify the mechanism in the next section.

Figure 2 shows that financial liberalization is associated with faster GDP growth. The figure depicts GDP growth rates in MECs before and after financial liberalization, after controlling for initial income per capita and population growth. ${ }^{4}$ This simple graphical representation reveals two patterns: first, growth is on average more rapid in open country episodes than in closed ${ }^{5}$ second, in almost every country the open episode exhibits more rapid growth than the closed episode. ${ }^{6}$

\footnotetext{
${ }^{4}$ Only one growth rate is shown for countries that were open or closed throughout the period. Country episodes of less than five years are excluded.

5 Exceptions are China, which performed better than predicted in spite of being closed, and Greece, which is an underperforming open economy.

${ }^{6}$ Here an exception is Indonesia, which grew marginally less rapidly during the open period. However, given Indonesia's major crisis in the postliberalization period, the fact that it recorded a growth rate above the predicted value in the second period is still remarkable. Note that even in cases (such as Brazil and the Philippines) where the growth rate is less than predicted, the gap between the actual and the predicted value is smaller in the open period.
} 
Figure 2: Liberalization and Growth

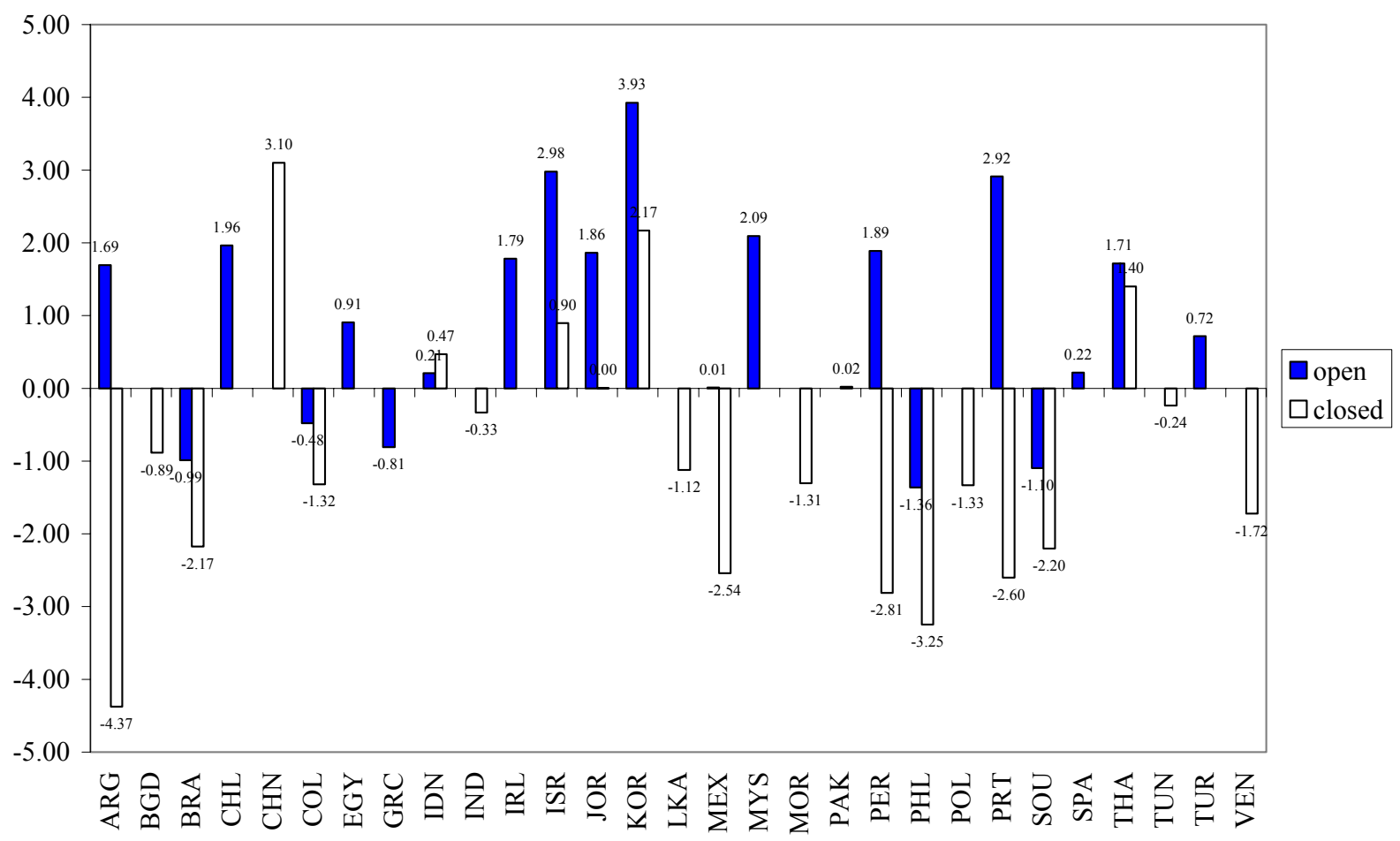

Note: The country episodes are constructed using windows of different length for each country. Country episodes that are shorter than 5 years are excluded. Averaging over these periods, we estimate a simple growth regression by OLS in which real per capita growth is the dependent variable and that only include the respective initial income and population growth. The figure plots the residuals from this regression.

Source: Population growth for Portugal: IMF, IFS. All other series: WDI, World Bank.

In order to assess the link between liberalization and growth, we add our liberalization variables to a standard growth regression:

$$
\Delta y_{i t}=\lambda y_{i, \text { ini }}+\gamma X_{i t}+\phi_{1} T L_{i t}+\phi_{2} F L_{i t}+\varepsilon_{j t}
$$

where $\Delta y_{i t}$ is the average growth rate of GDP per capita; $y_{i, \text { ini }}$ is the initial level of GDP per capita; $X_{i t}$ is a vector of control variables that includes initial human capital, the average population growth rate, and life expectancy; and $T L_{i t}$ and $F L_{i t}$ are our trade and financial liberalization indicators, respectively. We do not include investment among the control variables, because we expect trade and financial liberalization to affect GDP growth through higher investment.

We estimate the regression in three different ways. First, we estimate a standard cross-sectional regression by ordinary least squares. In this case 1980 is the initial year. $T L_{i t}$ and $F L_{i t}$ take values between 0 and 1 , specifying the share of years that the country was liberalized during our sample period $\{0,0.05$, $0.1, \ldots, 1\}$. Second, we estimate a panel regression using two nonoverlapping windows of time: 1980-89 and 1990-99. Here the liberalization variables again take a value between 0 and 1 during each subperiod. Lastly, we use overlapping time windows as in Bekaert, Harvey, and Lundblad. For each country and each 
variable, we construct ten-year averages starting with the period 1980-89 and rolling forward to the period 1990-99. Thus each country has up to ten data points in the time-series dimension. In this case the liberalization variables take values in the interval $[0,1]$, depending on the proportion of liberalized years in a given window. We estimate the panel regressions using generalized least squares. We deal with the resulting autocorrelation in the residuals by adjusting the standard errors according to the method of W. Newey and K. West. ${ }^{7}$

Table 1 reports the estimation results. The financial liberalization variable enters significantly at the 5 percent level in all regressions in which it appears. The cross-sectional regression (column 1-1) shows that, following financial liberalization, growth in GDP per capita increases by 2.4 percentage points a year, after controlling for the standard variables. The corresponding estimates are 1.7 percentage points in the nonoverlapping panel regression (column 1-2) and 2.5 percentage points in the overlappingwindows regression (column 1-3). The last regression is similar to those estimated by Bekaert, Harvey, and Lundblad using stock market liberalization dates. They find that GDP growth increases in the range of 0.4 to 1.5 percentage points.

Table 1. Regressions Explaining Growth in GDP per Capita with Trade and Financial Liberalization ${ }^{\mathrm{a}}$

\begin{tabular}{lcccccc}
\hline Independent variable & $1-1^{\mathrm{b}}$ & $1-2^{\mathrm{c}}$ & $1-3^{\mathrm{d}}$ & $1-4^{\mathrm{d}}$ & $1-5^{\mathrm{d}}$ & $1-6^{\mathrm{e}}$ \\
\hline Financial liberalization & $2.363^{* *}$ & $1.691^{* *}$ & $2.502^{* *}$ & & $2.777^{* *}$ & $2.278^{* *}$ \\
& $(0.533)$ & $(0.603)$ & $(0.101)$ & & $(0.115)$ & $(0.172)$ \\
& & & & & & \\
& & & & $1.784^{* *}$ & $1.606^{* *}$ & $0.147^{* *}$ \\
Trade liberalization & & & & $(0.155)$ & $(0.105)$ & $(0.021)$ \\
& & & & & & \\
Summary statistics: & 0.546 & 0.633 & 0.692 & 0.544 & 0.747 & 0.802 \\
Adjusted $R^{2 \mathrm{f}}$ & 34 & 59 & 290 & 300 & 280 & 440 \\
No. of observations & & & & & & \\
\hline
\end{tabular}

Source: Authors' regressions.

a. The estimated equation is equation 1 in the text; the dependent variable is the average annual growth rate of real GDP per capita. Control variables include initial per capita income, secondary schooling, population growth, and life expectancy. Standard errors are reported in parentheses and are adjusted for heteroskedasticity according to Newey and West (1987). ** indicates significance at the 5 percent level.

b. Standard cross-sectional regression estimated by ordinary least squares for the period 1980-99.

c. Nonoverlapping panel regression estimated by generalized least squares (GLS) with two periods, 1980-89 and 199099.

d. Overlapping panel regression estimated by GLS with data as ten-year averages starting with 1980-89 and rolling forward to 1990-99.

e. Same as column 1-5 but with the addition of high-enforceability countries.

f. The adjusted $R^{2}$ is likely to overestimate the share of the variance explained by our right-hand-side variables because of the overlapping nature of the regression. No method comparable to that of Newey and West for the standard errors exists for adjusting the $R^{2}$, and therefore the values need to be interpreted carefully.

\footnotetext{
${ }^{7}$ Newey and West (1987). Our panel is unbalanced because not all series are available for all periods. Our source of data is the
} 
Column 1-4 in table 1 shows that, following trade liberalization, GDP growth increases 1.8 percentage points a year. This estimate is similar to the 2-percentage-point increase found by Sachs and Warner. ${ }^{8}$ Notice that the increase in GDP growth is greater following financial liberalization than following trade liberalization. Moreover, column 1-5 shows that when we include both variables in the growth regression, the marginal effect of trade liberalization falls to 1.6 percentage points, whereas that of financial liberalization increases (to 2.8 percentage points). The larger effect of financial liberalization suggests that, in addition to the productivity gains from trade liberalization, the easing of financial constraints has been an important source of growth. The effect of financial liberalization will be the focus of the model we present below. Finally, column 1-6 shows that the positive link between liberalization and growth is also evident in the larger sample that includes HECs as well as MECs.

To deal with the possible endogeneity of the liberalization variables, table B3 in appendix B reports estimation results from two-stage least squares regressions using as instruments the legal origin index of Rafael La Porta and others, ${ }^{9}$ as well as lagged values of all the variables in the regression. The table also reports results of regressions with fixed effects and of regressions excluding China and Ireland, which may be driven by other factors. Our benchmark results in the first three columns are robust to these different estimation methods. The following stylized fact summarizes our findings.

Stylized fact 2. Over the period 1980-99 both trade liberalization and financial liberalization are associated with more rapid growth in GDP per capita across the set of countries with functioning financial markets.

The existing literature provides mixed evidence on whether openness promotes long-run growth. ${ }^{10}$ This can be attributed either to the indicators of openness used or to the sample considered. We find a statistically significant link for two reasons. First, we identify liberalization dates that allow us to compare performance during liberalized country-years with that during nonliberalized ones. Second, we restrict our analysis to the set of countries that have functioning financial markets, because only in these countries do we expect our mechanism to work.

In contrast, many papers that do not find a significant link use de jure liberalization indexes or de facto indexes that do not identify liberalization dates. However, the de jure indexes currently available

\footnotetext{
World Development Indicators of the World Bank. See appendix B for the specific sources.

${ }^{8}$ Sachs and Warner (1995).

${ }^{9}$ La Porta and others (1999).

${ }^{10}$ See, for instance, Bekaert, Harvey, and Lundblad (2001), Chari and Henry (2002), Dollar and Kraay (2002), Edison and others (2002), Edwards (1998), Eichengreen (2001), Frankel and Romer (1999), Gourinchas and Jeanne (2003), Prasad and others (2003), Quinn (1997), and Rodrik (1998).
} 
for a large set of countries do not accurately reflect countries' de facto access to international financial markets. A country that has liberalized de jure may not implement the new policy for many years or may simply lack access to international financial markets despite having liberalized. For example, some African countries are de jure more financially liberalized than most Latin American countries yet have much smaller international financial flows. Several de facto "openness indexes" measure the size of some capital flow categories over the sample period. But because these openness indexes do not identify a specific year of liberalization, they are not appropriate for comparing the behavior of macroeconomic variables before and after liberalization.

\section{Liberalization and Financial Fragility}

We have shown that both trade and financial liberalization are associated with faster long-run growth across countries with functioning financial markets. Financial liberalization has often been criticized on the grounds that it leads to crises, which are bad for growth. This argument is neither empirically nor conceptually correct: that financial liberalization leads to infrequent crises does not mean that financial liberalization is bad for growth over the long run. We will show that financial liberalization does indeed lead to a greater incidence of crisis. Then we will show that the average positive link between liberalization and growth documented above is not driven by those rapid-growth countries that have had no crises. Instead, countries that grow faster tend to have crises. That is, there is a strong statistical link between the incidence of crises and long-run growth. This finding does not imply that crises are good for (or cause) growth.

The model we present in the appendix will show that, in the presence of severe credit market imperfections, the forces that generate financial deepening and growth also generate - as a by-productfinancial fragility. Because financial liberalization generates both financial deepening and crises, any analysis of the effects of financial liberalization must weigh its benefits against its costs. In short, it would be a mistake to reject financial liberalization by focusing only on its costs and its tendency to lead to crises.

To address systematically the issues discussed above, we need a measure of financial fragility. Unfortunately, no existing indexes of financial fragility are comparable across countries. In keeping with the spirit of this paper, we use instead a de facto measure of fragility: negative skewness of credit growth. That is, we capture the existence of fragility by one of its symptoms: infrequent, sharp, and abrupt falls in credit growth. These abrupt falls occur during the banking crises that are characteristic of the boom-bust cycles that typically follow financial liberalization. During the boom, bank credit expands very rapidly and excessive credit risk is undertaken. As a result, the economy becomes financially fragile and prone to 
crisis. Although the likelihood that a lending boom will crash in a given year is low, many lending booms do eventually end in a crisis. ${ }^{11}$ During such a crisis, new credit falls abruptly and recuperates only gradually.

It follows that a country that experiences a boom-bust cycle exhibits rapid credit growth during the boom, a sharp and abrupt fall during the crisis, and slow credit growth during the credit crunch that develops in the wake of the crisis. Since credit does not jump during the boom, and crises happen only occasionally, in financially fragile countries the distribution of credit growth rates is characterized by negative outliers. In statistical terms, countries that experience boom-bust cycles exhibit a negatively skewed distribution of credit growth. In plain language, the path of credit growth is "bumpy."12

\section{Figure 3: Credit Growth Distributions}

a) Kernel Densities:
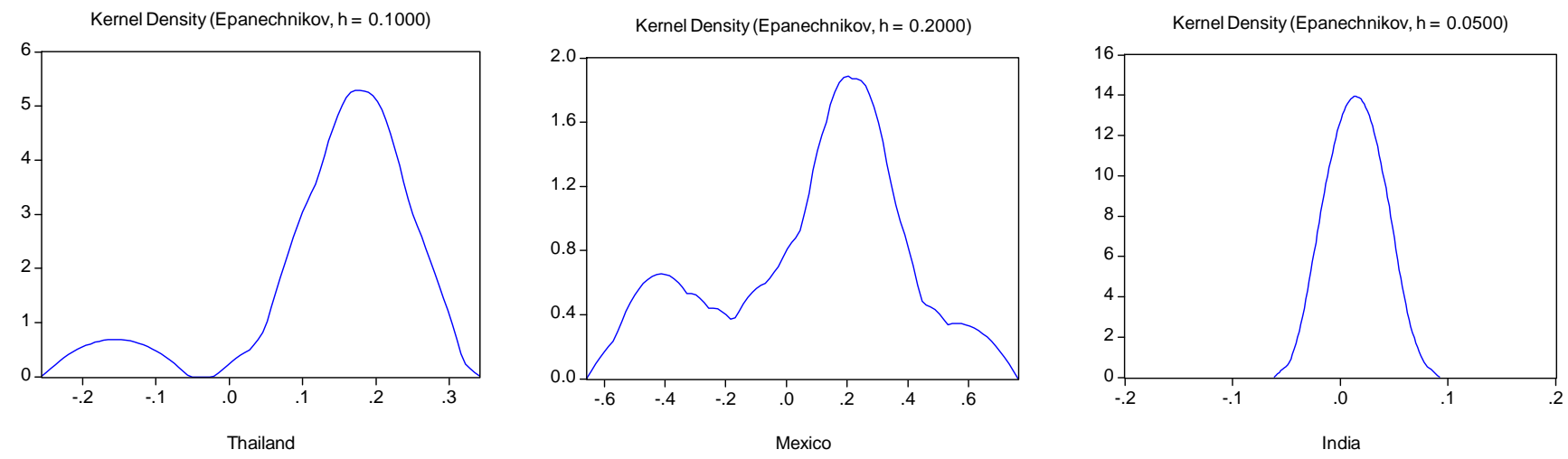

b) Descriptive Statistics:

\begin{tabular}{lccc}
\hline \hline & Thailand & Mexico & India \\
\hline Mean & 0.143 & 0.091 & 0.014 \\
Std. & 0.110 & 0.303 & 0.014 \\
Skewness & -1.945 & -0.537 & 0.157 \\
\hline \hline
\end{tabular}

Note: The sample period is $1988-1999$.

If we had infinite data series, the financial liberalization index would be an ideal measure of financial fragility. But in a finite sample the index may overlook some cases of fragility that do notyet - reflect bumpiness. Because most MECs that have followed risky credit paths experienced at least

\footnotetext{
${ }^{11}$ On the link between lending booms and crises see Gourinchas, Landerretche, and Valdes (2001), Kaminski and Reinhart (1999), Sachs, Tornell, and Velasco (1996a), and Tornell and Westermann (2002). See Bordo and Eichengreen (2002) for a historical perspective.

${ }^{12}$ During a lending boom a country experiences positive growth rates that are above normal. However, these are not positive outliers because the lending boom takes place for several years, and so most of the distribution is centered around a very high mean. Only a positive one-period jump in credit would create a positive outlier in growth rates and generate positive skewness. For instance, the increase in capital inflows that takes place when a country liberalizes might generate such positive skewness.
} 
one major crisis during our sample period (1980-99), we find that negative skewness of credit growth is a good indicator of the riskiness of the credit path followed by a given country.

Figure 3 depicts the kernel distributions of credit growth rates for India, Mexico, and Thailand. ${ }^{13}$ Credit growth in India, a typical example of a nonliberalized country, has a low mean, and the data are quite tightly distributed around the mean, with skewness close to zero. Meanwhile credit growth in Thailand, a prime example of a liberalized economy, has a very asymmetric distribution and is characterized by negative skewness. Mexico, like Thailand, has a very asymmetric distribution, and its mean is closer to that of Thailand than to that of India.

Table 2 shows that the link between financial liberalization and bumpiness holds more generally across MECs. The table partitions country-years into two groups: years before financial liberalization and years after. The table shows that financial liberalization leads to an increase in the mean of credit growth of 4 percentage points (from 3.8 percent to 7.8 percent) and a fall in the skewness of credit growth from near zero to -1.08 , and has only a negligible effect on the variance of credit growth. This illustrates the following stylized fact.

Stylized fact 3. Across MECs financial liberalization has been followed by financial deepening. This process, however, has not been smooth but is characterized by booms and occasional busts.

\section{Table 2. Moments of Credit Growth before and after Financial Liberalization ${ }^{\mathrm{a}}$}

\begin{tabular}{lcc}
\hline Moment & $\begin{array}{c}\text { Liberalized } \\
\text { Country-years }\end{array}$ & $\begin{array}{c}\text { Nonliberalized } \\
\text { Country-years }\end{array}$ \\
\hline MECs & & \\
Mean & 0.078 & 0.038 \\
Standard deviation & 0.151 & 0.170 \\
Skewness & -1.086 & 0.165 \\
& & \\
HECs & & \\
Mean & 0.025 & $\ldots$ \\
Standard deviation & 0.045 & $\ldots$ \\
Skewness & 0.497 & $\ldots$ \\
\hline
\end{tabular}

Source: Authors' calculations.

a. The sample is partitioned into two country-year groups: liberalized and nonliberalized. Before the standard deviation and skewness are calculated, the means are removed from the series and data errors for Belgium, New Zealand, and the United Kingdom are corrected for.

\footnotetext{
${ }^{13}$ The simplest nonparametric density estimate of a distribution of a series is the histogram. A histogram, however, is sensitive to the choice of origin and is not continuous. We therefore choose the more illustrative kernel density estimator, which smoothes the bumps in the histogram (see Silverman, 1986). Smoothing is done by putting less weight on observations that are further from the point being evaluated. The kernel function by Epanechnikov is given by $(3 / 4)\left[1-(\Delta B)^{2}\right] I(|\Delta B| \leq 1)$, where $\Delta B$ is the growth rate of real credit and $I$ is an indicator function, which takes the value of 1 if $|\Delta B| \leq 1$ and zero otherwise.
} 
Notice that, across HECs, credit growth exhibits near-zero skewness, and both the mean and the variance are smaller than across MECs. As we will argue below, this difference reflects the absence of severe credit market imperfections in HECs.

The effect of financial liberalization on the mean and the bumpiness of credit growth is represented visually in the event study in figure 4. The top panel shows the deviation of the credit-to-GDP ratio, after liberalization, from its mean in normal times (that is, the years not covered by the dummy variables in the regression). Over the six years following the liberalization date, the credit-to-GDP ratio increases on average by 6 percentage points, and this cumulative increase is significant at the 5 percent level. The bottom panel shows the increase in negative skewness, which reflects the increase in bumpiness. ${ }^{14}$ Here the average negative skewness increases from about zero to -2.5 , which is also significant at the 5 percent level.

In the literature, variance is the typical measure of volatility. We choose not to use variance to identify growth-enhancing credit risk because a high variance of credit growth reflects not only the presence of boom-bust cycles, but also the presence of high-frequency shocks. This may lead to false inferences about the links among liberalization, fragility, and growth. In the sample we consider, this problem is particularly acute because high-frequency shocks are more abundant than the rare crises that punctuate lending booms.

In short, variance is not a good measure for distinguishing economies that have followed risky, growth-enhancing credit paths from those that have experienced high-frequency shocks. By contrast, negative skewness of credit growth is a good indicator of the incidence of occasional crises. There might be other, more complex indicators of crises. We have chosen skewness because it is a parsimonious way to capture the existence of risky credit paths. Furthermore, it complements the variance in the regressions we estimate by allowing us to distinguish between "good" volatility (bumpiness) and "bad" volatility (variance). ${ }^{15}$

\footnotetext{
${ }^{14}$ Skewness is computed over a ten-year period. Since the event window is based on only ten data points, we consider a shorter window.

${ }^{15}$ Skewness is sufficient to identify a risky path. High kurtosis may come on top of it, but it is neither necessary nor sufficient. The combination of the two is sufficient but identifies the extreme cases only. For instance, it does not capture many countries that have experienced boom-bust cycles (such as Chile, Mexico, and Turkey). Kurtosis could in principle provide further information about the distribution. However, in practice it is not useful in identifying the risky and the safe paths. If there is a single, short-lived crisis, an outlier in the distribution leads to a long tail on the left and a high kurtosis. However, if there is autocorrelation in the growth rates and the crisis is somewhat persistent, or if there is more than one crisis, the distribution becomes bimodal, and kurtosis can easily become very low. It is therefore an excessively sensitive measure of bumpiness. Depending on the degree of autocorrelation in the shocks, it could be anything from one to infinity (the kurtosis of a normal distribution is equal to 3). In principle, one could argue that other low-frequency shocks affect both safe and risky economies. Therefore skewness could pick up countries that did not undertake credit risk but had exogenous negative low-frequency shocks that led to a negatively skewed distribution. We are not aware that such shocks have hit MECs during the last two decades. Veldkamp (2002) has used skewness to analyze asset price crashes.
} 
Figure 4: Financial Liberalization, Lending Booms and Bumpiness

a) Credit/GDP

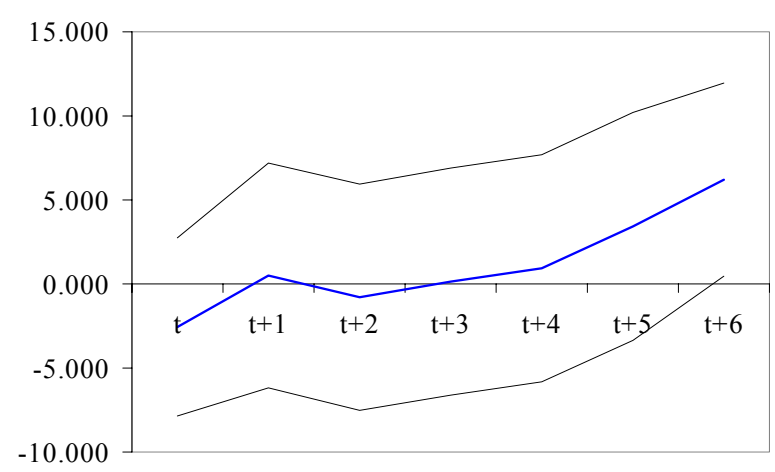

b) Skewness

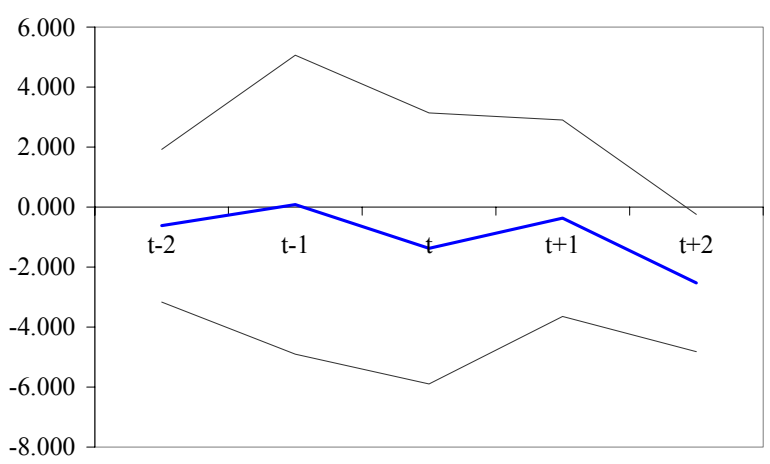

Note: In panel b) skewness refers to the skewness of real credit growth in the following 10 years. The event windows were constructed from panel regressions of the respective variable on dummy variables that take of value of 1 in the period where a country liberalized and zero otherwise. The panel regressions are estimated with fixed effects, using a GLS estimator.

Source: Own calculations.

\section{Financial Fragility and Growth}

We have shown that trade liberalization is typically followed by financial liberalization, which in turn leads not only to financial deepening but also to booms and busts. On the one hand, in an economy with severe credit market imperfections, financial deepening is good for growth because financing constraints are eased. On the other hand, crises are bad for growth because they generate systemic insolvencies and fire sales. Ultimately, which of these two effects dominates is an empirical question. The following stylized fact summarizes the results that will be discussed below.

Stylized fact 4. Over the last two decades countries with bumpy credit paths have grown faster than those with smooth credit paths, when the standard variables are controlled for.

Our results are foreshadowed by figure 5, which shows the link between GDP growth and the moments of credit growth across MECs, controlling for initial GDP and population growth. Rapid longrun GDP growth is associated with a higher mean growth rate of credit, lower variance, and negative skewness.

As the figure shows, countries that have followed a risky path, such as Chile, Korea, and Thailand, exhibit negatively skewed credit growth and rapid GDP growth. In contrast, countries that have followed a safe path do not exhibit negative skewness and have slow growth; examples are Bangladesh, Morocco, and Pakistan. China and Ireland are notable exceptions: they have experienced very rapid GDP growth in the last twenty years but have not experienced a major crisis despite a high rate of credit growth. 
Figure 5: Moments of Credit and GDP Growth

a) Growth and Mean

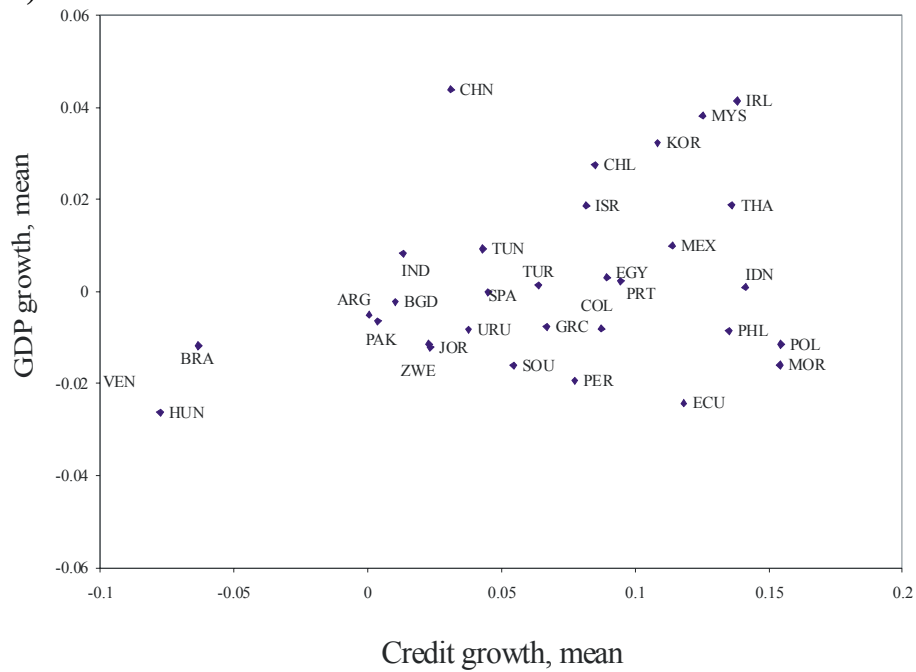

b) Growth and Variance

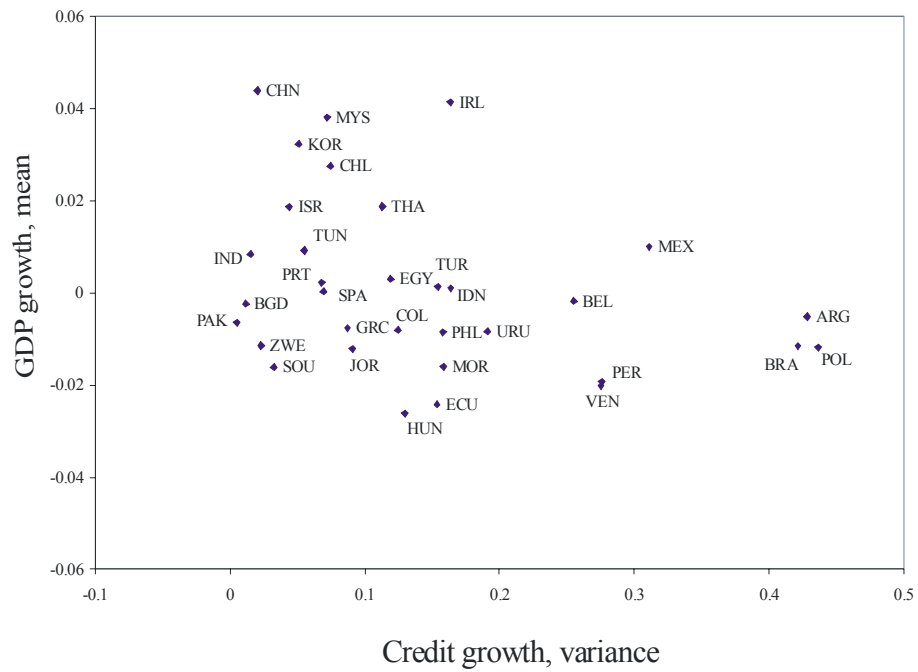

c) Growth and Skewness

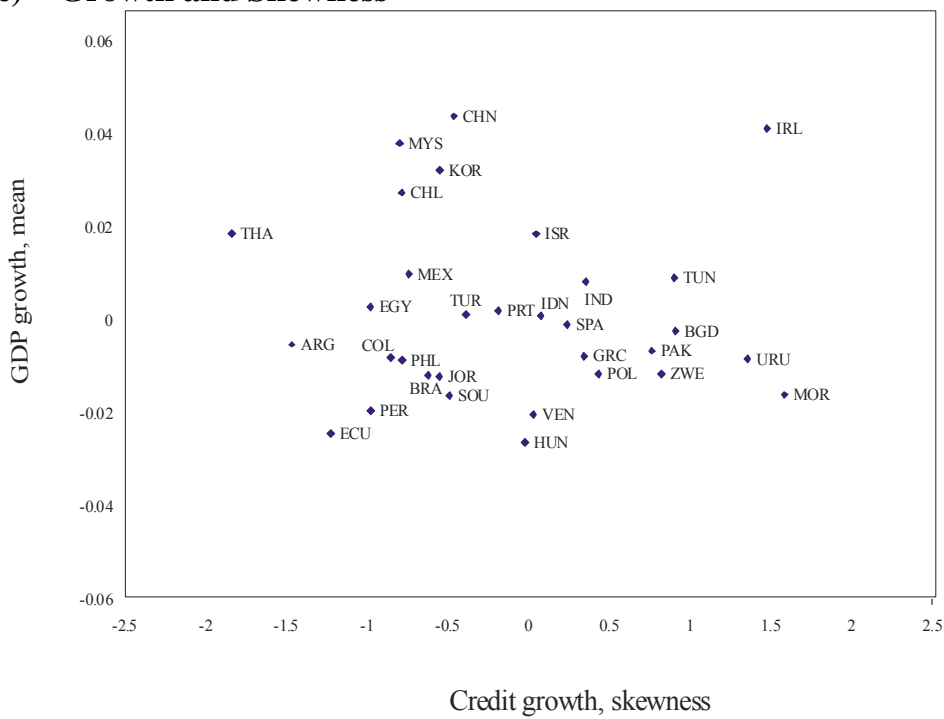

Note: The graphs plot the moments of real credit growth during the period 1988-1999 against the residuals of a growth regres controls for initial per capita GDP and population growth. 
In order to assess the link between bumpiness and growth, we add the three moments of real credit growth to the regression in equation 1:

$$
\text { (2) } \Delta y_{i t}=\lambda y_{i, \text { ini }}+\gamma X_{i t}+\beta_{1} \mu_{\Delta B, i t}+\beta_{2} \sigma_{\Delta B, i t}+\beta_{3} S_{\Delta B, i t}+\phi_{1} T L_{i t}+\phi_{2} F L_{i t}+\varepsilon_{j, t},
$$

where $\Delta y_{i t}, y_{i, \text { ini }}, X_{i t}, T L_{i t}$, and $F L_{i t}$ are defined as in equation 1 , and $\mu_{\Delta B, i t}, \sigma_{\Delta B, i t}$, and $S_{\Delta B, i t}$ are the mean, standard deviation, and skewness of the real credit growth rate, respectively. We do not include investment as a control variable because we expect the three moments of credit growth, our variables of interest, to affect GDP growth through higher investment.

We estimate equation 2 using the same type of overlapping panel data regression as for equation 1. For each moment of credit growth and each country, we construct ten-year averages starting with the period 1980-89 and rolling forward to the period 1990-99. Similarly, the liberalization variables take values in the interval [0,1], depending on the proportion of liberalized years in a given window. ${ }^{16}$ Given the dimension of equation 2, the overlapping-windows regression is the most appropriate method for the analysis we perform here. ${ }^{17}$

Table 3. Regressions Explaining Growth in GDP per Capita with Moments of Credit Growth ${ }^{\mathrm{a}}$

\begin{tabular}{lcccc}
\hline Independent variable & $3-1^{\mathrm{b}}$ & $3-2^{\mathrm{c}}$ & $3-3^{\mathrm{b}}$ & $3^{\mathrm{c}} 4^{\mathrm{c}}$ \\
\hline Mean of real credit growth rate & $0.170^{* *}$ & $0.154^{* *}$ & $0.093^{* *}$ & $0.110^{* *}$ \\
& $(0.012)$ & $(0.009)$ & $(0.007)$ & $(0.009)$ \\
Standard deviation of real & $-0.029^{* *}$ & $-0.030^{* *}$ & $-0.014^{* *}$ & $-0.019^{* *}$ \\
credit growth rate & $(0.007)$ & $(0.003)$ & $(0.003)$ & $(0.004)$ \\
Negative skewness of real & $0.174^{* *}$ & $0.266^{* *}$ & $-0.095^{*}$ & $0.135^{* *}$ \\
credit growth rate & $(0.069)$ & $(0.021)$ & $(0.053)$ & $(0.031)$ \\
Financial liberalization & & & $1.894^{* *}$ & $1.811^{* *}$ \\
& & & $(0.122)$ & $(0.163)$ \\
Trade liberalization & & & $0.838^{* *}$ & $0.895^{* *}$ \\
& & & $(0.155)$ & $(0.198)$ \\
Summary statistics: & & & & \\
Adjusted $R^{2 \mathrm{~d}}$ & & & & \\
No. of observations & 269 & 424 & 253 & 408 \\
\hline
\end{tabular}

a. Equation 2 in the text is estimated using panel data and generalized least squares; the dependent variable is the average annual growth rate of real GDP per capita. Standard errors are reported in parentheses and are adjusted for heteroskedasticity according to Newey and West (1987). Control variables include initial per capita income, secondary schooling, population growth, and life expectancy. ** indicates significance at the 5 percent level.

b. Sample includes MECs only.

c. Sample includes HECs and MECs.

d. The adjusted $R^{2}$ is likely to overestimate the share of the variance explained by our right-hand-side variables because of the overlapping nature of the regression. No method comparable to that of Newey and West for the standard errors exists for adjusting the $R^{2}$, and therefore the values need to be interpreted carefully.

\footnotetext{
${ }^{16}$ Since the higher moments of credit growth cannot be computed in a meaningful way when the observations are few, we consider only series for which we have at least ten years of data.

17 The overlapping-windows regression captures the spirit of the model we present below for the following reason. In the risky equilibrium of a liberalized economy there is a probability $1-u$ that a crisis will occur at time $t+1$, given that a crisis does not occur at $t$. Meanwhile, in a nonliberalized economy, the probability of crisis is always zero. Therefore, according to the model, ten-year windows with more liberalized years should exhibit both greater negative skewness and more rapid growth than windows with fewer liberalized years.
} 
Table 3 reports the estimation results. Consistent with the literature, we find that, after controlling for the standard variables, the mean growth rate of credit has a positive effect on long-run GDP growth, and the variance of credit growth has a negative effect. Both variables enter significantly at the 5 percent level in all regressions. ${ }^{18}$

The first key point established in table 3 is that the credit that accompanies rapid GDP growth is bumpy. Columns 3-1 and 3-2 show that bumpy credit markets are associated with higher growth rates across countries with functioning financial markets. That is, negative skewness - a bumpier growth pathis on average associated with faster GDP growth. This estimate is significant at the 5 percent level. ${ }^{19}$

To interpret the estimate of 0.27 for bumpiness, consider India, which has near-zero skewness, and Thailand, which has a skewness of -2. A point estimate of 0.27 implies that an increase in the bumpiness index of 2 (from zero to -2) increases the average long-run GDP growth rate by 0.54 percentage point a year. Is this estimate economically meaningful? To address this question, note that, after controlling for the standard variables, Thailand grows about 2 percentage points faster per year than India. Thus about a quarter of this growth differential can be attributed to credit risk taking, as measured by the skewness of credit growth. ${ }^{20}$

One can interpret the negative coefficient on variance as capturing the effect of "bad" volatility generated by, for instance, procyclical fiscal policy. ${ }^{21}$ Meanwhile the positive coefficient on bumpiness captures the "good" volatility associated with the type of risk taking that eases financial constraints and increases investment. Notice that a country with high variance need not have negative skewness. ${ }^{22}$

The second key point is that the association between bumpiness and growth does not imply that crises are good for growth. Crises are costly. They are the price that has to be paid in order to attain faster growth in the presence of credit market imperfections. To see this, consider column 3-3 in table 3. When the financial liberalization indicator is included in the growth regression, bumpiness enters with a negative sign (and is significant at the 10 percent level). In the MEC set, given that there is financial liberalization, the lower the incidence of crises, the better. We can see the same pattern in

\footnotetext{
${ }^{18}$ The link between financial deepening and growth is well established in the literature. See, for instance, Demirguc-Kunt and Levine (2001) and Levine, Loayza, and Beck (2000). See also the seminal work of McKinnon (1973).

${ }^{19}$ Notice that the estimated coefficient on bumpiness is not capturing country fixed effects. Recall that, for each country, skewness varies over time, like all other variables, as we use ten-year rolling averages.

${ }^{20}$ In order to deal with the possible endogeneity of the skewness variable, table B3v in Appendix B reports estimation results of two-stage least squares regressions using as instruments the legal origin index of La Porta et. al. (1999), as well as lagged values of all variables in the regression. Furthermore, table 16 reports results of regressions with fixed effects and of regressions excluding China and Ireland, which may be driven by other factors. Our benchmark results in column 3-2 are robust to these different estimation methods.

${ }^{21}$ Ramey and Ramey (1995) and Fatas and Mihov (2002) show that fiscal policy-induced volatility is bad for economic growth.

${ }^{22}$ Imbs's (2002) results are consistent with this view.
} 
the sample that includes HECs as well as MECs: the point estimate of bumpiness in column 3-4 is lower than that in column $3-2 .^{23}$

Clearly, liberalization without fragility is best, but the data suggest that this combination is not available to MECs. Instead, the existence of contract enforceability problems implies that liberalization leads to higher growth because it eases financial constraints but, as a by-product, also induces financial fragility. Despite the rare occurrence of crises, on net, financial liberalization has led to more rapid long-run growth, as shown by the estimates in tables 1 and 3 .

\section{Identifying the Mechanism: Sectoral Asymmetries and the Boom-Bust Cycle}

We have documented statistically significant correlations between liberalization and growth; among liberalization, financial deepening, and bumpiness; and between the latter two and growth. But what mechanism underlies these links? Which way does the causation run?

Appendix A presents a model that establishes a causal link from liberalization to financial deepening and GDP growth. Furthermore, the same forces that generate growth also generate financial fragility, which leads to rare crises. The theoretical mechanism has unambiguous implications for the behavior of credit and the ratio of $\mathrm{N}$-sector to T-sector output. Testing whether these predictions are confirmed by the data will help identify the direction of causation.

We start by describing the model intuitively. We then explain how the model accounts for the main features of the typical boom-bust cycle experienced by MECs, and after that we test the predictions of the model regarding the N-to-T output ratio. Finally, we discuss why the evidence strongly supports the view that causation goes from liberalization to growth and not the other way around.

\section{The Mechanism}

We consider a two-sector economy in which there are asymmetries in financing opportunities across sectors. T-sector firms have perfect access to international capital markets. Meanwhile, N-sector financing is subject to two credit market imperfections: contract enforceability problems and systemic bailout guarantees.

Enforceability problems arise because managers of $\mathrm{N}$-sector firms cannot commit to repaying debt: they are able to divert funds to themselves by incurring a cost. As a result, in the model, lenders impose on each N-sector firm a borrowing constraint that is proportional to its cash flow. This setup captures the fact that, across MECs, T-sector firms can, in general, access international capital markets more easily than most $\mathrm{N}$-sector firms. The latter are financially constrained and dependent on domestic

${ }^{23}$ The reason why bumpiness enters with a positive sign in the fourth column is that all HECs are liberalized and have near zero 
bank credit (except for the largest firms, which are in telecommunications, energy and finance). ${ }^{24}$ Since trade and financial liberalization have typically not been accompanied by judicial reform, enforceability problems have remained. Thus liberalization has exacerbated the asymmetric financing opportunities across sectors.

The second imperfection found in MECs is that financial liberalization not only lifts restrictions that preclude risk taking but also is associated with explicit and implicit bailout guarantees that protect creditors against the effects of systemic crises. Because domestic banks have been the prime beneficiaries of these guarantees, this has created incentives for investors to use domestic banks to channel resources to firms that cannot pledge international collateral. Thus liberalization has resulted in biased capital inflows. T-sector firms and very large N-sector firms are the recipients of FDI and portfolio flows, whereas most of the inflows that end up in the N-sector are intermediated through domestic banks, which enjoy systemic bailout guarantees.

A key result of the model is that systemic guarantees may induce banks and their clients to take on credit risk, but they do not eliminate borrowing constraints. Why does this happen? Systemic guarantees are promises to step in and repay debt obligations only in case of widespread insolvencies. If there is systemic risk in the economy, agents can exploit the subsidy implicit in the guarantees by undertaking credit risk. If a borrower defaults in a state of the world where many other borrowers are also defaulting, lenders will get repaid in full by the bailout agency. Because the market anticipates this contingent subsidy, taking on credit risk reduces the cost of capital. Thus borrowers will find it profitable to take on credit risk if the probability of insolvency is small enough. At the same time, guarantees do not neutralize enforceability problems, and thus borrowing constraints are not eliminated. This is because a bailout is not granted when only a few borrowers default. ${ }^{25}$

How is this systemic risk generated? Over the past few decades, credit risk has become common in bank and corporate balance sheets in MECs in the form of short maturities and currency mismatches. As a result, an important share of banks' liabilities is denominated in foreign currency, whereas their assets are either denominated in domestic currency or are loans to the N-sector. If a reversal of capital inflows were to occur, there would be a real depreciation, fire sales, and a meltdown of bank balance sheets. It is in these circumstances that bailouts are generally granted. In other words, the

skewness. Thus, negative skewness acts like a dummy that selects MECs that have liberalized financially.

${ }^{24}$ There are several reasons why T-sector firms can access international financial markets more easily than N-sector firms. For instance, since T-sector firms tend to export, they can more easily establish long-term relationships with foreign firms, and they can pledge export receivables as collateral. Also, on average, T-sector firms are larger than N-sector firms.

${ }^{25}$ This is why it is important to distinguish systemic from unconditional guarantees, which are granted whenever there is an individual default. Notice that if all guarantees were unconditional, enforceability problems would not generate borrowing constraints, because a bailout would be granted whenever there is a single default, regardless of the state of the world. The results in this paragraph are proved in Schneider and Tornell (forthcoming). 
interaction of contract enforceability problems and systemic bailout guarantees sets in motion a selfreinforcing mechanism. On the one hand, the expectation of real exchange rate variability makes it optimal for agents to denominate debt in foreign currency and run the risk of going bankrupt. On the other hand, the resulting currency mismatch at the aggregate level makes the real exchange rate variable, validating agents' expectations. ${ }^{26}$

We have seen that, in the presence of contract enforceability problems, the credit of most Nsector firms is constrained by their cash flow, even though there are bailout guarantees. This happens because guarantees are systemic, so that lenders will lend only as much as they are sure that the borrower will be willing to repay. A second key observation is that taking on credit risk reduces expected debt repayments because the bailout agency will cover part of the debt obligation in the event of a systemic crisis. Thus the bailout guarantee allows financially constrained firms to borrow more than they could otherwise. This increase in borrowing and investment is accompanied by an increase in credit risk. When many firms take on credit risk, aggregate financial fragility rises, together with $\mathrm{N}$-sector investment and growth.

Faster N-sector growth helps the T-sector grow faster because N-sector goods are used in Tsector production. Therefore the T-sector will enjoy more abundant and cheaper inputs than otherwise. As a result, as long as a crisis does not occur, growth in a risky economy is faster than in a safe one. This does not, however, guarantee that, in the long run, average growth in a risky economy is also faster than in a safe one, because financial fragility implies that a self-fulfilling crisis may occur, in which case GDP growth will fall.

As we show in appendix A, if crises are rare events, average long-run growth will be faster along a risky path than along a safe path unless the costs of a crisis are excessively high. In fact, if crises were not rare, agents would not find it profitable to take on credit risk in the first place. This explains why financial fragility leads to faster mean GDP growth.

The argument has thus established a joint causal link: financial liberalization promotes both long-run growth and financial fragility. Since, in any equilibrium, crises both are rare and result in an abrupt and drastic fall in credit, which recuperates only gradually, credit growth will be negatively skewed if the time sample is long enough. Thus negative skewness of credit growth is a symptom of financial fragility. This explains why skewness of credit growth is a valid right-hand-side variable in the regressions we estimate.

Before moving on to the other predictions of the model, we emphasize that both guarantees and enforceability problems are essential to the argument. If there were no guarantees, agents would not

\footnotetext{
${ }^{26}$ From a theoretical perspective, several other self-reinforcing mechanisms link credit risk with aggregate financial fragility.
} 
be willing to take on credit risk to claim the implicit subsidy. Alternatively, if contract enforceability problems were not severe enough, borrowing constraints would not arise in equilibrium, and if enforceability problems were too severe, firms could not attain enough leverage, and systemic risk would not arise. To link these remarks to the data, we note that explicit and implicit systemic bailout guarantees are present in most countries. They capture the "too big to fail" principle: when a systemic meltdown occurs, governments tend to grant bailouts. ${ }^{27}$ The degree of contract enforceability varies from country to country. We have identified those countries where contract enforceability problems are not too severe as those where the stock market turnover-to-GDP ratio was greater than 1 percent in 1998. We partition this set into countries with either a high or a medium degree of contract enforceability (HECs and MECs) as described earlier. The mechanism we have described is operative only in the MEC set.

\section{The Boom-Bust Cycle and the Bottleneck Effect}

In addition to helping us identify the mechanism that links liberalization, fragility, and longrun growth, an attractive feature of our approach is that it can account for higher-frequency phenomena, such as the boom-bust cycles typically experienced by MECs, and the bottleneck effect. This will allow us, in the next section, to evaluate the Mexican performance.

We represent the typical boom-bust cycle by means of an event study. Figure 6 shows the average behavior, across our set of thirty-five MECs, of several macroeconomic variables around twin currency and banking crises during the period 1980-99. Year 0 refers to the year during which twin currency and banking crises take place. ${ }^{28}$ In each panel the heavy line represents the average deviation relative to tranquil times, the dotted lines represent the 95 percent confidence interval, and the thin lines correspond to Mexico. $^{29}$

We focus on currency mismatches because they capture the recent experience of MECs.

27 One might argue that, in the aftermath of crises, guarantees cease to exist temporarily (for instance, because of fiscal constraints). However, after a few years they come back. One might also argue that regulations precluding fraud or extreme risk taking might be imposed as a result of a crisis. In terms of the model of appendix A, we would say that, in that case, systemic guarantees are still in place, but either regulations do not allow agents to exploit them or there is a shift in expectations in the wake of the crisis (that is, agents believe that others will not take on credit risk, and so a meltdown and hence a bailout cannot take place in the next period).

${ }^{28}$ We say that there is a twin crisis at year 0 if both a currency and a banking crisis occur during that year, or if one occurs at year 0 and the other at year 1 .

${ }_{29}$ The graphs are the visual representations of the point estimates and standard errors from regressions in which the variable depicted in the graph is the dependent variable, regressed on time dummies preceding and following a crisis. We estimate the following pooled regression:

$$
y_{i t}=a_{i}+\sum \beta_{j} \text { Dummy }_{\tau+j}+\varepsilon_{i t},
$$

where $y$ is the variable of interest in the graph; $i=1, \ldots, 35$ denotes the country; $t=1980, \ldots, 1999$; and Dummy ${ }_{\tau+j}$ equals 1 at time $\tau+j$ and zero otherwise, where $\tau$ is a crisis year. The panel data estimations account for differences in the mean by allowing for fixed effects, as well as for differences in the variance by using a generalized least squares estimator, using the estimated cross-sectional residual variances. 
Figure 6: The Boom-Bust Cycle of the average MEC

\section{Credit/GDP}

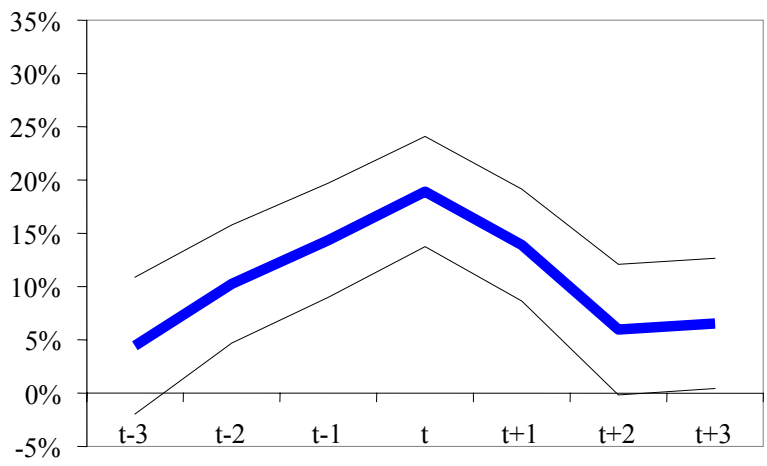

\section{Exports Growth}

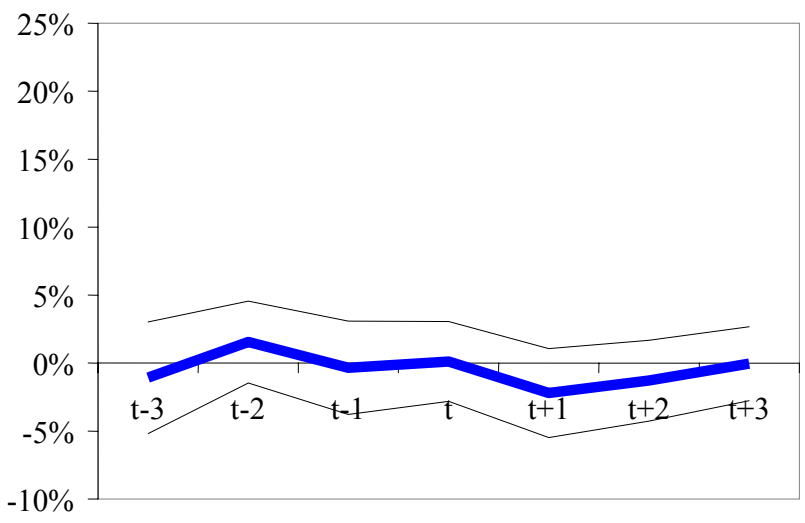

Investment

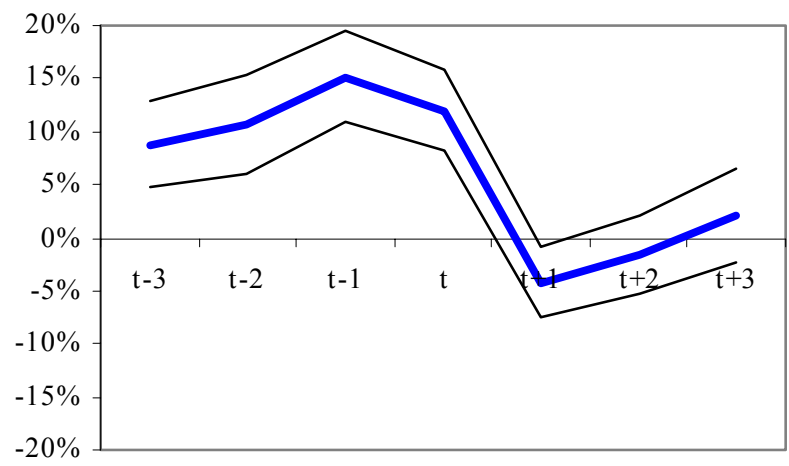

N-to-T Output Ratio

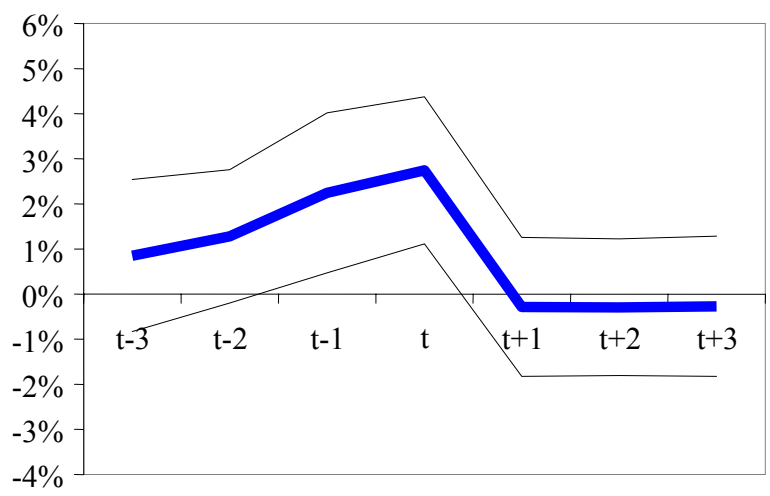

GDP per Capita Growth

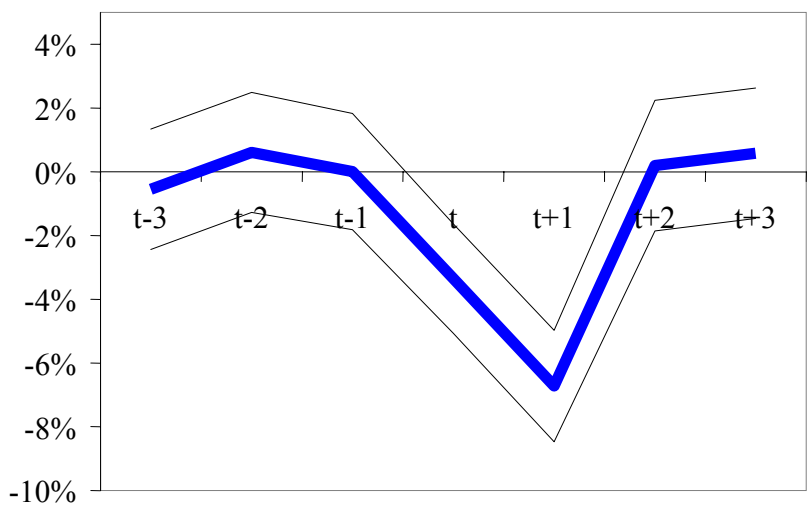

Consumption

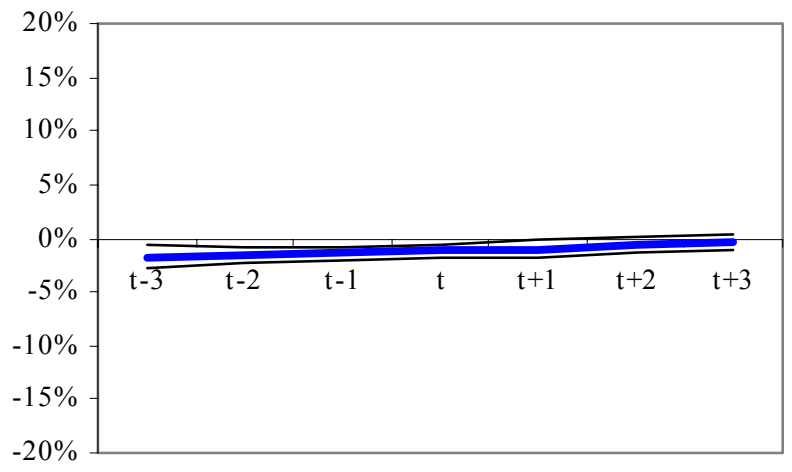




\section{Figure 6 (continuation)}

\section{Real Appreciation}

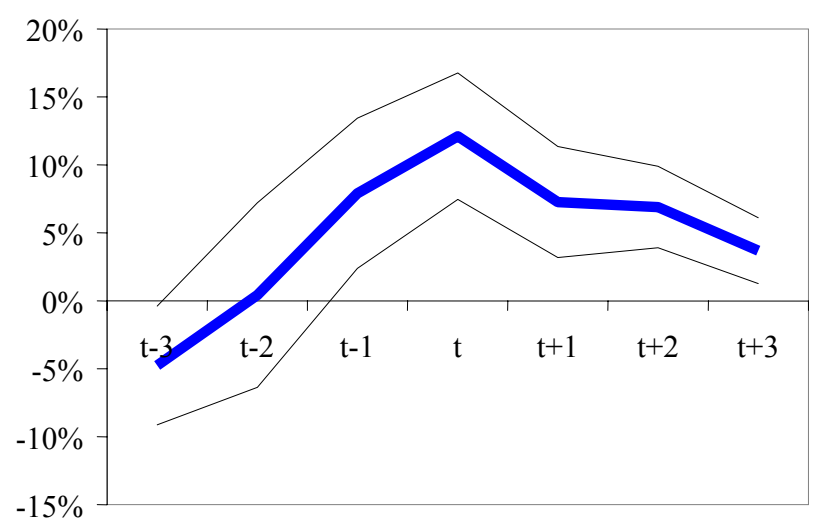

Typically, before a crisis there is a real appreciation and a lending boom, during which credit grows unusually fast. During the crisis there is a drastic real depreciation, which coincides with a meltdown of the banking system, widespread insolvencies, and fire sales. In the aftermath of the crisis there is typically a short-lived recession and a fall in credit that is both sharper and longer-lasting than the fall in GDP. Thus the credit-to-GDP ratio declines.

The milder fall in aggregate GDP than in credit masks the asymmetric sectoral response we emphasize in this paper: N-sector output falls more than T-sector output in the wake of a crisis and recuperates more sluggishly thereafter. This asymmetry is also present during the boom that precedes the crisis, as the $\mathrm{N}$-sector grows faster than the T-sector and a real appreciation occurs. ${ }^{30}$ Finally, the figure also shows that investment fluctuations are quite pronounced along the boom-bust cycle, whereas those of consumption are not.

The model can account for these features because financial constraints and credit risk (in the form of currency mismatches) coexist in equilibrium, and their interaction generates real exchange rate variability. In a risky equilibrium, currency mismatch is optimal and borrowing constraints bind, so that there can be a self-fulfilling, steep real depreciation that generates widespread bankruptcies of N-sector firms and the banks that lend to them. Because N-sector net worth falls drastically and recuperates only gradually, there is a collapse in credit and $\mathrm{N}$-sector investment, which take a long time to recuperate. Since T-sector firms do not face financial constraints, and the real depreciation allows them to buy inputs at fire-sale prices, this leads to rapid growth of T-sector output and GDP in the wake of the crisis. As a result, the N-to-T output ratio falls drastically and recuperates sluggishly.

\footnotetext{
${ }^{30}$ This asymmetric sectoral response parallels the regressions using the $\mathrm{N}$-to-T output ratio in the previous subsection.
} 
However, rapid GDP growth cannot be sustained over a long period if it is driven only by Tsector growth, because $\mathrm{T}$-sector production needs inputs from the $\mathrm{N}$-sector. If the credit crunch continues for a long period, depressed N-sector investment eventually leads to bottlenecks: the T-sector no longer enjoys an abundant and cheap supply of N-sector inputs, and its growth starts falling. This is the bottleneck effect, which implies that sustainable growth cannot be supported only by export growth. This effect is key to understanding Mexico's recent performance. ${ }^{31}$

\section{Sectoral Asymmetries}

We have shown that, in MECs, T-sector firms can in general access international markets and overcome these problems more easily than N-sector firms. This asymmetry in financing opportunities imposes restrictions on the behavior of credit and the response of the N-to-T output ratio to various shocks. Testing whether these restrictions are present in data from MECs will help us identify the mechanism that links liberalization and long-run growth.

First, consider the response of the N-to-T output ratio to trade and financial liberalization. Since trade liberalization benefits mostly T-sector firms and allows them to establish financing channels in international markets, the N-to-T output ratio should decrease following trade liberalization. Because financial liberalization is typically followed by a lending boom that benefits the financially constrained Nsector relatively more than the T-sector, the N-to-T output ratio should increase following financial liberalization.

Second, consider the response of the N-to-T output ratio to a crisis. The sharp real depreciation that occurs during crises worsens the balance sheets of the N-sector firms and leads to fire sales, which benefit the T-sector at the expense of the N-sector. Thus, the N-to-T output ratio falls in the wake of crises. Because N-sector credit is constrained by the sector's net worth, and because it takes a long time for that net worth to recover, the N-to-T output ratio might continue to fall for a prolonged period.

Third, because the N-sector is more financially constrained than the T-sector, and banks are highly exposed to the $\mathrm{N}$-sector, the $\mathrm{N}$-to- $\mathrm{T}$ ratio should move together with credit in normal times and should collapse together with credit during crises.

\footnotetext{
31 The fact that T-sector production uses N-sector inputs is key. This is an essential difference between our model and the standard dependent-economy model, where the linkage between the $\mathrm{N}$ - and the $\mathrm{T}$-sectors derives from the fact that both use the same nonreproducible factor. In such a model, rapid N-sector growth does not cause rapid T-sector growth, and there is no bottleneck effect. In the short run, a shock that negatively affects the N-sector's investment and output generates a real depreciation and benefits the T-sector in both models. In the medium run the predictions of the two models differ. In our model the T-sector will suffer a bottleneck as N-sector inputs become scarce. This is not the case in the dependent-economy model.
} 
To test whether these patterns are present in the data, we construct two different indexes of Nsector and T-sector production for our set of countries. We then estimate regressions of the following form:

$$
\Delta N / T_{i t}=c+\beta_{1} T L_{i t}+\beta_{2} F L_{i t}+\beta_{3} \text { credit }_{i t}+\sum_{j=0}^{5} \delta_{j} \operatorname{crisis}_{i, t+j}+\varepsilon_{i t},
$$

where $N / T_{i t}$ is the N-to-T output ratio in country $i$ at time $t$; credit ${ }_{i t}$ is real credit growth; $T L_{i t}$ and $F L_{i t}$ equal 1 if there has been trade or financial liberalization, respectively, in country $i$ in or before year $t$, and zero otherwise; and crisis ${ }_{i, t+j}$ equals 1 in country $i$ and year $t+j$, where $t$ denotes the year when twin banking and currency crises occur in country $i$, and $j$ denotes the number of years after the crisis. ${ }^{32}$

Table 4. Regressions Testing for Sectoral Asymmetries

\begin{tabular}{lccc}
\hline Independent variable & $4-1$ & $4-2$ & $4-3$ \\
\hline Financial liberalization & $1.147^{* *}$ & $0.989^{* *}$ & $1.007^{* *}$ \\
& $(0.140)$ & $(0.148)$ & $(0.141)$ \\
Trade liberalization & $-0.780^{* *}$ & $-0.581^{* *}$ & $-0.782^{* *}$ \\
& $(0.189)$ & $(0.198)$ & $(0.203)$ \\
Credit & & $0.481^{* *}$ & $0.440^{* *}$ \\
& & $(0.205)$ & $(0.192)$ \\
Rate of real depreciation & & & $2.233^{* *}$ \\
& & & $(1.372)$ \\
Crisis year dummy & $-0.243^{*}$ & $-0.205^{*}$ & $-0.274^{* *}$ \\
& $(0.143)$ & $(0.125)$ & $(0.121)$ \\
Crisis year +1 & $-2.434^{* *}$ & $-2.124^{* *}$ & $-2.228^{* *}$ \\
& $(0.143)$ & $(0.184)$ & $(0.177)$ \\
Crisis year +2 & $0.193^{*}$ & $0.439^{* *}$ & $0.370^{* *}$ \\
& $(0.127)$ & $(0.155)$ & $(0.147)$ \\
Crisis year +3 & $-0.793^{* *}$ & $-0.652^{* *}$ & $-0.693^{* *}$ \\
& $(0.127)$ & $(0.130)$ & $(0.122)$ \\
Crisis year +4 & $-0.499^{* *}$ & -0.248 & $-0.348^{*}$ \\
& $(0.192)$ & $(0.204)$ & $(0.194)$ \\
Crisis year +5 & $0.872^{* *}$ & $0.837^{* *}$ & $0.916^{* *}$ \\
& $(0.183)$ & $(0.162)$ & $(0.154)$ \\
Summary statistics: & & & \\
Adjusted $R^{2}$ & & & \\
No. of observations & 0.655 & 0.728 & 0.734 \\
\hline
\end{tabular}

a. Equation 3 in the text is estimated using panel data and generalized least squares; the dependent variable is the ratio of nontradables sector output to tradables sector output. Standard errors are reported in parentheses. * indicates significance at the 10 percent level, ${ }^{* *}$ at the 5 percent level.

Our first N-to-T output index is used in table 4. This index is constructed by looking at the behavior of the sectoral exports-to-GDP ratio. We consider construction, manufacturing, and services, and for each country we classify as the tradable sector the one of these three in which this ratio is the highest, and as nontradable the one in which the ratio is lowest. In appendix B we consider another index based on

${ }^{32}$ Rajan and Zingales (1998) examine the sectors in the United States that use external finance more intensively than others. They then test whether these same sectors have grown faster in countries that have experienced greater financial deepening. 
the variability of the sectoral real exchange rate. The correlation between both indexes is 0.74 , and the results of regressions using the two indexes are very similar.

We estimate equation 3 using the MEC sample in a panel data regression that includes fixed effects and uses a generalized least squares estimator. The sample covers the period from 1980 to 1999 with annual data. Column 4-1 in table 4 shows that, across MECs, the N-to-T output ratio responds in the way predicted by the model. The liberalization variables are significant at the 5 percent level in all regressions. The estimates show that the N-to-T output index falls following trade liberalization, whereas it increases following financial liberalization. The table also shows that the N-to-T output index falls in the wake of a crisis. The strongest effect is observed in the first period after the eruption of the crisis. After a small rebound in period $t+2$, the index continues to fall until $t+4$.

Consider now the link between bank credit and the N-to-T output ratio. As column 4-2 of table 4 shows, credit growth enters with a positive sign and is significant at the 5 percent level. This indicates that the co-movement of credit and the N-to-T output ratio is not conditional on the occurrence of either a crisis or policy reform. To control for the fact that the ratio can move in response to other shocks that generate movements in the real exchange rate, we also estimate equation 3 including the rate of real depreciation as an explanatory variable. As column 4-3 shows, both liberalization variables and credit remain significant at the 5 percent level when this variable is included. The crisis $i, t+j$ dummies enter significantly at the 5 percent level in almost all cases.

An alternative way to examine the close link between the $\mathrm{N}$-to-T output ratio and credit growth is through vector autoregressions (VARs). If we impose the restriction that output within a quarter is predetermined by past investment, and thus does not respond to variations in credit, our model implies that we can run bivariate VARs of credit with the N-to-T output ratio, or of credit with GDP. Figure 7 shows the impulse responses of the N-to-T output ratio and GDP to a 1-standard-deviation shock to real credit growth in Mexico and the United States. The contrast is impressive. In Mexico both GDP and the N-to-T output ratio react significantly to a credit shock even when the effects of crisis and liberalization are accounted for. ${ }^{33}$

By contrast, in the United States the effect of credit on GDP is only mildly significant and negligible in magnitude. Similarly, the effect on the N-to-T output ratio in the United States is smaller than in Mexico and not statistically significant. This difference is consistent with the view that contract enforceability problems are more severe in Mexico than in the United States. T-sector firms can overcome these problems, but most N-sector firms cannot, and this asymmetry is reflected in a strong response of the

\footnotetext{
${ }^{33}$ The crisis and liberalization dates have been dummied out in the VARs.
} 
N-to-T output ratio. Furthermore, this effect is strong enough to be reflected in aggregate GDP, which is the sum of $\mathrm{N}$-sector and $\mathrm{T}$-sector production.

Figure 7: Responses to a Credit Shock in Mexico and the USA
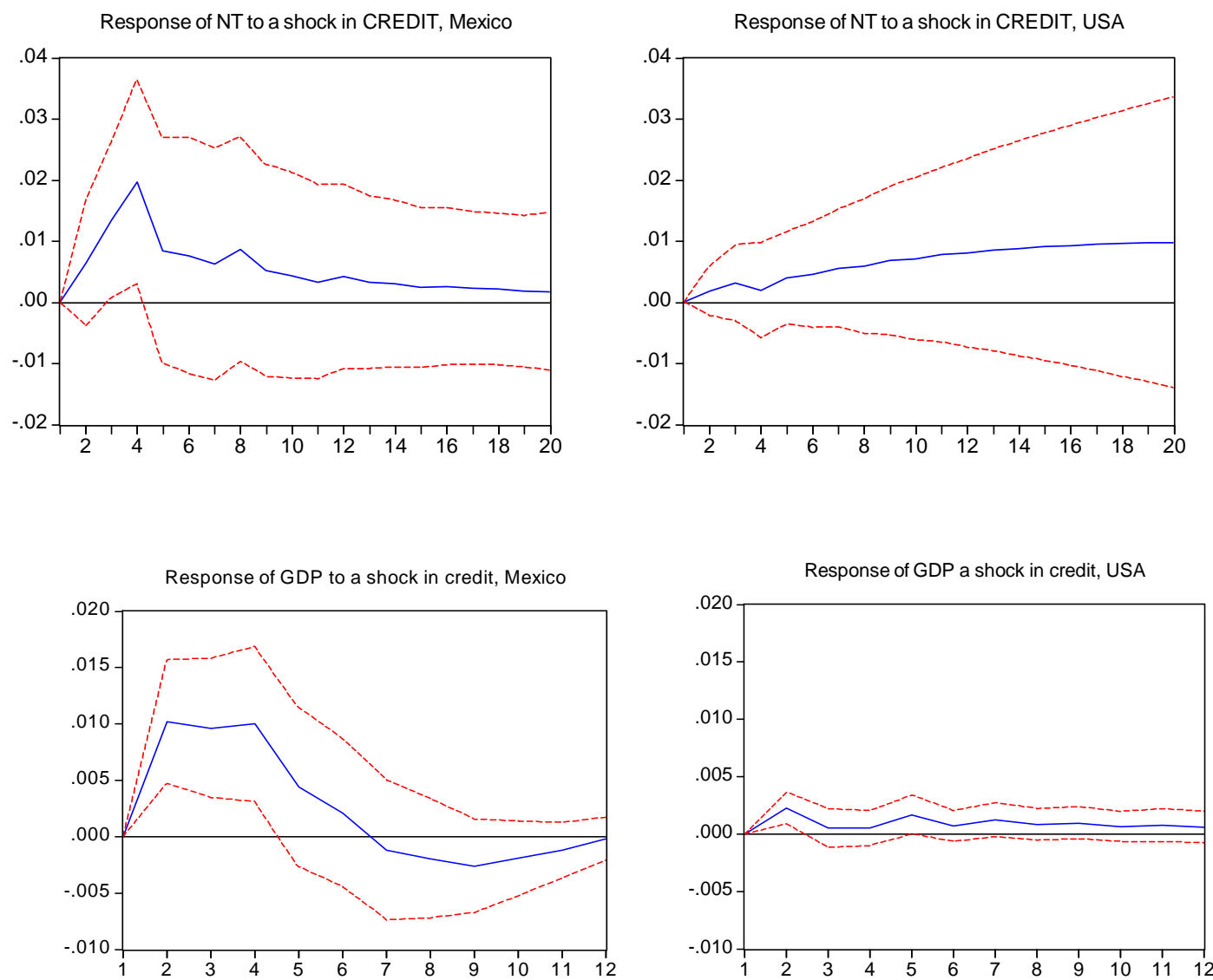

Note: The heavy lines trace the response of Mexico and the USA to a one-standard deviation shock in credit. Calculations are based on two-variable VARs, including credit and either GDP or the N-to-T output ratio. Each VAR is estimated from quarterly data in growth rates over the sample period from 1980:1 to 1999:4, allowing for 4 lags, a time trend and dummy variables for liberalization and the crisis. Finite sample critical values are generated by 1000 Monte Carlo replications.

\section{Are Other Mechanisms Consistent with the Data?}

We have presented a mechanism (based on the model presented in appendix A) in which causation runs from liberalization to growth, with financial fragility arising as a by-product: liberalization allows the undertaking of credit risk by financially constrained firms, most of which are in the N-sector. This eases borrowing constraints and increases GDP growth, but it also generates endogenous financial fragility. Thus a liberalized economy will experience occasional self-fulfilling crises, during which a real depreciation coincides with sharp falls in the credit-to-GDP and N-to-T output ratios, as financially constrained $\mathrm{N}$-sector firms are hit especially hard. 
This mechanism implies, first, that credit growth and the credit-to-GDP ratio are negatively skewed, experiencing sharp falls during the occasional crisis; second, that the N-to-T output ratio collapses during crises and moves in tandem with credit in normal times; and third, that the N-to-T output ratio responds positively to financial liberalization and negatively to trade liberalization. Our data analysis has shown that MECs have all these predicted characteristics.

Would we observe this behavior of credit and the N-to-T output ratio if causation went in another direction, or if financial constraints did not play a key role? Consider, for instance, an alternative view in which faster GDP growth causes liberalization and an increase in capital inflows and in credit growth. In such a framework, faster GDP growth would lead to a higher N-to-T output ratio following financial liberalization, to a greater incidence of crises, and to a protracted decline in the ratio in the wake of a crisis. We are not aware of any argument in which the causation runs from GDP growth to liberalization and financial fragility that is also able to explain these patterns and a negatively skewed credit growth path. ${ }^{34}$

Liberalization may increase long-run growth by improving the quality of institutions, for instance through a discipline effect that induces structural reforms that improve property rights and reduce taxation. ${ }^{35}$ This channel does not generate financial fragility, and it can work side by side with the mechanism we have identified here. ${ }^{36}$

Finally, the asymmetry in financing opportunities between the N- and T-sectors is key to our argument. In the next section we provide evidence from microlevel data from the Mexican economic census and stock market supporting this sectoral asymmetry. ${ }^{37}$

\section{Capital Flows}

During the last two decades, capital inflows to MECs have increased enormously, and so has the importance of private flows (figure 8). In the average MEC the share of private flows has increased from 60 percent in the mid-1980s to more than 90 percent by the end of the 1990 s.

FDI is considered a "good" form of capital inflow, whereas bank flows are considered "bad" because they are foreign loans to domestic banks. Such loans are risky because of the currency mismatch.

\footnotetext{
${ }^{34}$ Consider, for instance, the traditional dependent-economy model where the $\mathrm{N}$ - and T-sectors use a common, nonreproducible factor (such as labor or land) and where there are no credit market imperfections. There is no force in such an economy that would lead to a greater incidence of crises following financial liberalization, generate a negatively skewed credit growth distribution, or generate a protracted decline in the N-to-T output ratio in the wake of a crisis.

${ }^{35}$ As in Tornell and Velasco (1992).

${ }^{36}$ On this point see Kaminski and Schmukler (2002), Levine, Loayza, and Beck (2000), and Loayza and Ranciere (2002).

${ }^{37}$ Tornell and Westermann (2003) also provide evidence for this sectoral asymmetry for a set of MECs by looking at survey data from the World Bank.
} 
Figure 8: Capital Inflows

a) MECs

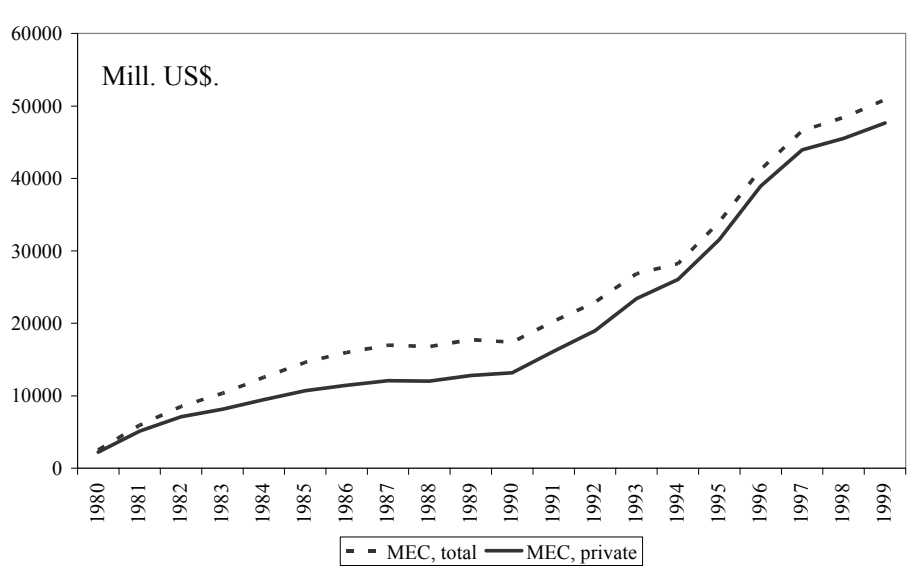

b) Mexico

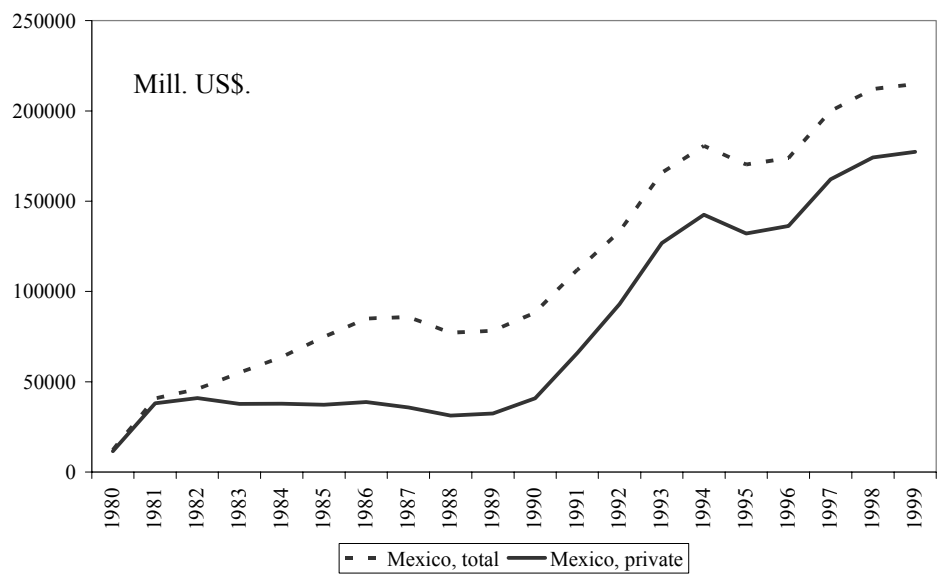

Note: The figures show the total accumulated financial inflows in Mill. US\$.

Source: International Financial Statistics, IMF.

\section{Figure 9: Components of Private Capital Inflows}

a) MECs

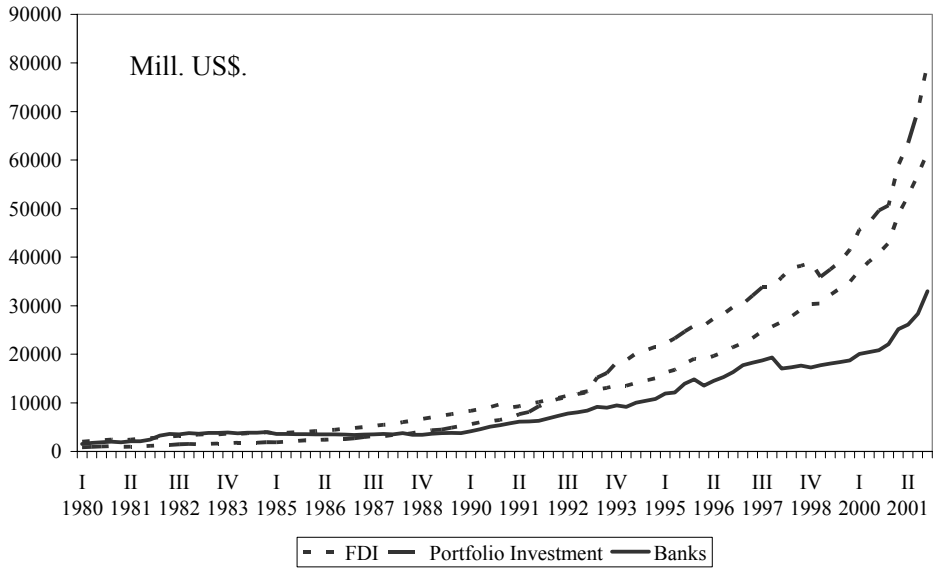

b) Mexico

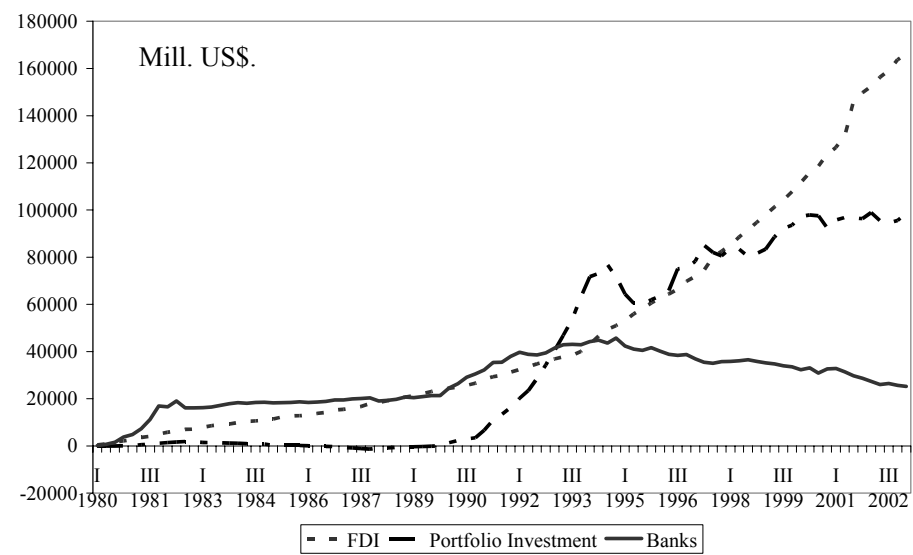

Note: Banks include commercial and development banks Source: IFS, IMF and Bank of Mexico

Several observers have noted that one reason why financial liberalization has led to financial fragility is that an important share of capital inflows takes the form of bank flows. Many have argued that the greater the share of inflows in the form of FDI and the lower the share of bank credit, the lower is financial fragility. To evaluate this argument we must keep in mind a key fact overlooked by the literature. 
Stylized fact 5. The lion's share of FDI is directed mostly to the T-sector or to financial institutions.

This is illustrated in Table 5. Because the nonfinancial N-sector receives a small share of FDI, bank flows remain the main source of external finance for most N-sector firms. Since this group of firms is financially constrained, a reduction in risky bank flows and credit may mean that N-sector investment and growth will fall. As there are productive linkages throughout the economy, the unconstrained T-sector will also be negatively affected. Hence it is possible that the net effect of banning risky bank flows is to reduce long-run GDP growth. Here again we see that, in the presence of credit market imperfections, a policy that reduces financial fragility can, as a by-product, lead to a fall in growth. ${ }^{38}$

Table 5. FDI Originating in the USA in 1998

\begin{tabular}{lccc}
\hline \hline & $\mathrm{N}$ & $\mathrm{T}$ & $\mathrm{F}$ \\
\hline All countries & 0.260 & 0.275 & 0.465 \\
HECs & 0.260 & 0.232 & 0.508 \\
MECs & 0.265 & 0.416 & 0.319 \\
Mexico & 0.154 & 0.592 & 0.255 \\
\hline \hline
\end{tabular}

Source: Bureau of Economic Analysis

\section{Lessons and Conclusions}

We have shown that trade liberalization is typically followed by financial liberalization, which leads to lending booms and occasional financial crises. On net, however, both trade and financial liberalization have led to faster long-run growth across the set of countries with functioning financial markets.

We have presented a model that establishes a causal link from liberalization to growth. Trade liberalization promotes efficiency and growth mainly in the tradables sector. Financial liberalization adds even more to growth because it eases financing constraints, leading to an increase in investment by financially constrained firms, most of which are in the nontradables sector. However, the easing of financing constraints takes place through the undertaking of credit risk, which leads to financial fragility and occasional crises.

\footnotetext{
${ }^{38}$ We do not analyze here how the new theories of FDI account for the stylized fact that the largest share of nonfinancial FDI is allocated to the T-sector. Vertical motives for FDI involve fragmentation of production across countries (Markusen, 2002). Horizontal motives for FDI imply that firms invest abroad when the gains from avoiding trade costs outweigh the costs of maintaining capacity in a foreign country. Helpman, Melitz, and Yeaple (2003) test this theory using U.S. data and find that the least productive firms serve only the domestic market, that relatively more productive firms export, and that the most productive firms engage in FDI. A third theory, based on the role of information in driving FDI, might also help account for this fact (Mody, Razin, and Sadka, 2003).
} 
We conclude with a list of seven lessons. First, although several observers have claimed that financial liberalization is not good for growth because of the crises associated with it, this is the wrong lesson to draw. Our empirical analysis shows that, across countries with functioning financial markets, financial liberalization leads to faster average long-run growth, even though it also leads to occasional crises. This gain in growth is over and above the gain derived from trade liberalization.

A second, closely related, lesson is that the growth-enhancing financial deepening that follows liberalization is not a smooth process. Rather, it takes place through boom-bust cycles. Occasional crises are the price that has to be paid to attain faster growth in the presence of severe contract enforceability problems. The first-best solution is to implement judicial reform and improve contract enforceability. In the absence of such reforms, liberalization permits financially constrained firms to attain greater leverage and invest more, at the cost of undertaking credit risk. Credit risk creates an environment of rapid growth and financial fragility.

Third, to analyze the effects of liberalization it is not sufficient to look at aggregate data alone. Sectoral asymmetries play a key role: many tradables (T-) sector firms have access to international capital markets, whereas most nontradables $(\mathrm{N}-)$ sector firms are financially constrained and depend on banks for their financing. Trade liberalization and agreements such as NAFTA promote faster productivity growth in the T-sector but are of little direct help to the N-sector. Financial liberalization leads to an increase in international bank flows, which allows financially constrained firms to borrow more. Since many of these firms are in the N-sector, a currency mismatch on firms' balance sheets develops, making the economy prone to self-fulfilling crises. In short, financial liberalization generates crises in countries with contract enforcement problems because financial liberalization is associated with international lending to the $\mathrm{N}$-sector.

We agree with the general view that FDI is the safest form of capital inflow. Our fourth lesson, however, is that FDI does not obviate the need for risky international bank flows. FDI goes mostly to T-sector firms and financial institutions. As a result, bank flows are practically the only source of external finance for most $\mathrm{N}$-sector firms. Curtailing such risky flows would reduce N-sector investment and generate bottlenecks that would limit long-run growth. Bank flows are hardly to be recommended, but for most firms it might be that or nothing. Clearly, allowing risky capital flows does not mean that anything goes. Appropriate prudential regulation must also be in place.

Fifth, it is possible for GDP growth to recover rapidly from a crisis. Sustainable growth, however, cannot be assured unless the banking problem is fixed. Recovery in aggregate activity is typically not uniform across the economy. The tradables sector may grow strongly while the nontradables sector recuperates only sluggishly. This asymmetric response is intimately linked to a 
severe credit crunch that hits the N-sector particularly hard and that goes hand in hand with a steady increase in the share of nonperforming loans.

A sixth lesson is that crises are part of the growth process in financially liberalized countries with contract enforcement problems. At the "tipping point," beyond which it is unlikely that capital outflows will reverse, authorities should focus on what to do after the crisis instead of attempting to forestall the crisis. Delaying an inevitable crisis will tend to make the effects of the fullblown crisis far worse, as attested by the experiences of Mexico in 1994 and Argentina in 2001.

Finally, one can draw a lesson for empirical implementation. Statistical variance is not a good instrument with which to identify financial fragility. Fragility is associated with infrequent but severe crises and therefore with both high variance and negative skewness. High variance, however, may reflect high-frequency shocks, which may be exogenous or self-inflicted, for instance by bad economic policy. Negative skewness tests specifically for infrequent crises. Our argument has shown that infrequent crises are a by-product of a rapid-growth path. 


\section{Appendix A}

\section{The Model}

Here, we formalize the intuitive argument of Section 3 and show that it is indeed part of an internally consistent story. The equilibrium will establish a causal link from financial liberalization to financial fragility, and from the latter to credit and GDP growth. Also, it will impose restrictions on the sample of countries over which the mechanism is operative, and on the behavior of credit and the N-to-T output ratio. The model is based on Schneider and Tornell (2003), and Ranciere, Tornell and Westermann (2003). ${ }^{60}$

We consider a simple dynamic general equilibrium model of an economy with two sectors: a tradables $(\mathrm{T})$ sector that produces the consumption good, and a nontradables $(\mathrm{N})$ sector that produces an intermediate good which is used as an input in the production of both goods. ${ }^{57}$ As we shall see, the fact that the N-sector demands its own goods is key for financial fragility to arise in equilibrium. The assumption that T-production uses N-inputs is key to generate the bottleneck effect and to link financial fragility to higher GDP growth. ${ }^{58}$

We will denote the relative price of $\mathrm{N}$-goods (i.e., the inverse of the real exchange rate) by $p_{t}=p_{t}^{N} / p_{t}^{T} \cdot{ }^{59}$ T-goods are produced using a nontradable input $\left(d_{t}\right)$ according to $y_{t}=a_{t} d_{t}^{\alpha}$, with $\alpha \in(0,1)$. In any equilibrium it follows that T-output and the T-sector demand for $\mathrm{N}$-goods are, respectively:

$$
y_{t}=a_{t} d_{t}^{\alpha}, \quad d\left(p_{t}\right)=\left(\frac{\alpha a_{t}}{p_{t}}\right)^{\frac{1}{1-\alpha}}
$$

\footnotetext{
${ }^{60}$ The model combines elements of the financial accelerator framework (Bernanke, et. al. (2000)) with elements of third-generation BoP crises models. See for instance, Aghion, et.al. (2000), Burnside, et.al. (2000), Caballero and Krishnamurthy (1999), Calvo (1998), Chang and Velasco (1998), Corsetti, et.al. (1999), Krugman (1999), Mckinnon and Pill (1998), and Tirole (2002).

${ }^{57}$ The assumption that $\mathrm{N}$-goods are demanded by the $\mathrm{N}$-sector is necessary to get financial fragility in equilibrium. The assumption that T-production uses N-inputs will allows us to formalize the bottleneck effect and to link financial fragility to higher GDP growth.

${ }^{58}$ Since the economy is small and open, the destination of T-goods is not important for our argument.

${ }^{59}$ Betts and Kehoe (2001) find that in a set of 52 countries over the period 1980-2000 real exchange rate variations reflect mainly changes in the relative price of $\mathrm{N}$ and $\mathrm{T}$ goods, not movements in the international relative prices of T-goods. Among some developed countries the latter channel is more important (Engel (1999)).
} 
$\mathrm{N}$-goods are produced using $\mathrm{N}$-goods as inputs $\left(I_{t}\right)$ according to

$$
q_{t+1}=\theta I_{t}
$$

The investable funds of an N-firm consist of the debt it issues $\left(B_{t}\right)$ plus its cash flow $\left(w_{t}\right)$. The firm's budget constraint, in terms of T-goods, is thus

$$
p_{t} I_{t}=w_{t}+B_{t}
$$

In order to allow for the possibility of financial fragility we assume that there are two oneperiod debt instruments. N-debt $\left(b_{t}^{n}\right)$, that promises to repay in N-goods: $p_{t+1}\left(1+\rho_{t}^{n}\right) b_{t}^{n}$; and T-debt $\left(b_{t}\right)$ that promises to repay in T-goods: $\left(1+\rho_{t}\right) b_{t}$. We can interpret $\mathrm{T}(\mathrm{N})$-debt as foreign(domestic) currency denominated debt. As we shall see, the price may take two values in equilibrium. Since firms produce N-goods, N-debt is a perfect hedge, while T-debt may be risky.

In modeling the N-sector we will make two assumptions to capture key features of MECs discussed in Section 3. First, N-sector financing is subject to contract enforceability problems. Second, there are systemic bailout guarantees that cover lenders against systemic meltdowns. ${ }^{60}$ We follow Schneider and Tornell (2003) and model the contract enforceability problem by assuming that firms are run by dynasties of two-period lived managers that cannot commit to repay debt: if at time $t$ the young manager incurs a non-pecuniary cost $h\left[w_{t}+B_{t}\right]$, then at $t+1$ she will be able to divert all the returns provided the firm is solvent. ${ }^{61}$ Lenders only finance plans that do not lead to diversion. Thus, when deciding whether to lend they take into account that the goal of every manager is to maximize next period's expected profits net of diversion costs.

\footnotetext{
${ }^{60}$ Recall the distinction between unconditional and systemic guarantees we made earlier. If all debt were covered by unconditional bailout guarantees, then the enforceability problem would become irrelevant and borrowing constraints would not arise in equilibrium.

${ }^{61}$ We can think of N-firms as banks that lend to the N-sector. This captures the fact that in MECs banks are heavily exposed to the $\mathrm{N}$-sector. The banking system is the channel through which capital inflows reach the $\mathrm{N}$-sector and also is the weak link during crises.
} 
The firm is solvent next period if revenues $q_{t+1} p_{t+1}$ are no lower than the promised debt repayment $L_{t+1}$ plus the young manager's wage $(1-\beta) p_{t+1} q_{t+1}$. In this case the old manager distributes the remaining profits, $\pi_{t+1}=\beta q_{t+1} p_{t+1}-L_{t+1}$, as a dividend to herself. To capture the costs of financial meltdowns we assume that under insolvency a large share $1-\mu_{w}$ of revenues are dissipated, the young manager gets a small amount of seed money $\mu_{w} p_{t+1} q_{t+1}$, with $\mu_{w}<1-\beta$, and the old manager gets zero. Lenders get $L_{t+1}$ if a bailout is granted and zero otherwise. Since guarantees are systemic, bailouts are paid out if and only if many borrowers go bust. For concreteness, we assume that there is a bailout agency that repays lenders $100 \%$ of what they were promised $\left(L_{t}\right)$ if a majority of borrowers goes bust. ${ }^{62}$

To close the description of the economy we note that the real exchange rate is determined by the N-goods market clearing condition

$$
d_{t}\left(p_{t}\right)+I_{t}\left(p_{t}\right)=q_{t}\left(I_{t-1}\right)
$$

Since there are no exogenous shocks, the only source of risk is endogenous real exchange rate variability. As we shall see, there are equilibria where $(7)$ holds at two values of $p_{t}$ : $\bar{p}_{t+1}$ if firms are solvent or $\underline{p}_{t+1}$ if they are insolvent. ${ }^{63}$

Trade and financial liberalization will mean a reduction in impediments to trade goods and assets, rather than a shift away from autarky. In a financially non-liberalized economy there are regulations that preclude agents from taking on credit risk that might lead to insolvency. Since the only source of risk is real exchange rate variability, this is equivalent to allowing agents to issue only N-debt. Financial liberalization eliminates these regulations, so agents can issue both types of debt. As we shall see, liberalization will lead to currency mismatch and lending booms that end in busts. The effects of trade liberalization are not the focus of the model. Since these reforms typically increase T-sector efficiency, they can

\footnotetext{
${ }^{62}$ Here we do not analyse how the cost of the subsidy implicit in the guarantees is paid for. This cost could be financed by domestic taxation if we assumed that T-goods were produced using a fixed factor. In this case the cost of the subsidy would be paid for by taxing this fixed factor. This is done by Ranciere, et.al. (2003).

${ }^{63}$ There are multiple self-fulfilling equilibria as in Cole and Kehoe (2000) and Obstfeld (1986).
} 
be represented by an increase in the productivity parameter $a_{t}$ in (4). To isolate the effects of financial liberalization we will set $a_{t}$ to one. ${ }^{64}$

Financing and Investment Decisions. Consider first a non-liberalized economy. Since lenders are risk neutral and the opportunity cost of capital is $1+r$, the interest rate that they require satisfies $\left[1+\rho_{t}^{n}\right] E_{t}\left(p_{t+1}\right)=1+r$. Furthermore, to avoid diversion by the firm, lenders impose a borrowing constraint: $(1+r) b_{t}^{n} \leq h\left(w_{t}+b_{t}^{n}\right)$. If investment yields a return which is higher than the opportunity cost of capital, the firm will borrow up to an amount that makes the credit constraint binding. Thus, budget constraint (6) implies that credit and investment are:

$$
b_{t}^{n}=\left[m^{s}-1\right] w_{t} \quad I_{t}=m^{s} \frac{w_{t}}{p_{t}}, \quad \text { where } m^{s}=\frac{1}{1-h \delta}, \quad \delta \equiv \frac{1}{1+r} .
$$

Notice that a necessary condition for borrowing constraints to arise is $h<1+r$. If $h$, the index of contract enforceability, were greater than the cost of capital, it would always be cheaper to repay debt rather than to divert. Thus, lenders will not impose a ceiling on the amount they are willing to lend and agents will not be financially constrained. This is why in the empirical part we differentiate high- $h$ from low- $h$ countries.

Consider now a liberalized economy. Firms can now choose between N- and T-debt. If there is enough real exchange rate variability, T-debt is risky and it might lead to insolvency: $\pi\left(\underline{p}_{t+1}\right)=\beta \underline{p}_{t+1} q_{t+1}-\left(1+\rho_{t}\right) b_{t}<0$. A firm might choose T-debt and risk insolvency because risky T-debt is cheaper than safe N-debt. To see why suppose for a moment that tomorrow's real exchange rate can take on two values. With probability $u$ it takes an appreciated value $\left(\bar{p}_{t+1}\right)$ that leaves every firm solvent, while with probability $1-u$ it takes a depreciated value $\left(\underline{p}_{t+1}\right)$ that makes all N-sector firms go bust and generates a crisis. Since lenders constrain credit to ensure that borrowers will repay in the no-crisis state, it follows that in the no-crisis

\footnotetext{
${ }^{64}$ Clearly, in the real world financial liberalization opens the possibility for agents to take on credit risk in many other ways than by just allowing them to choose a risky debt instrument. Here, we capture this in a parsimonious way that allows us to obtain closed-form solutions, which in turn allows us to make clear why in an economy with credit market imperfections financial liberalization leads to higher growth only if it leads to fragility.
} 
state debt is repaid in full and there is no bailout. Meanwhile, in the crisis state there is bankruptcy and each lender receives a bailout equal to what he was promised. Thus, the interest rate on $\mathrm{T}$-debt is $1+\rho_{t}=1+r$, while that on $\mathrm{N}$-debt is $1+\rho_{t}^{n}=\frac{1+r}{u \bar{p}_{t+1}+(1-u) \underline{p}_{t+1}}$. It follows that choosing $\mathrm{T}$-debt over $\mathrm{N}$-debt reduces the cost of capital from $1+r$ to $[1+r] u$. Lower expected debt repayments, in turn, ease the borrowing constraint as lenders will lend up to an amount that equates $u[1+r] b_{t}$ to $h\left[w_{t}+b_{t}\right]$. Therefore, credit and investment are:

$$
b_{t}=\left[m^{r}-1\right] w_{t} \quad I_{t}=m^{r} \frac{w_{t}}{p_{t}}, \quad m^{r}=\frac{1}{1-u^{-1} h \delta}
$$

By comparing (9) with (8) we can see that:

Result 1. In the presence of systemic bailout guarantees, risky currency mismatch allows agents to reduce the expected value of debt repayments, which eases borrowing constraints and increases the investment multiplier: $m^{r}>m^{s}$.

This increase in leverage is possible because systemic guarantees mean that in a crisis lenders expect to be bailed out. The fact that T-debt is cheaper than N-debt does not imply that agents will always be willing to issue T-debt. This is because with probability $1-u$ T-debt will result in bankruptcy for a borrower. One can show that it is individually optimal to choose T-debt if crises are rare events and there is enough real exchange rate variability:

$$
\frac{\beta \theta \bar{p}_{t+1}}{p_{t}} \geq \frac{1}{\delta}>h>\frac{\beta \theta \underline{p}_{t+1}}{p_{t}}
$$

This condition ensures that in the good state returns are high enough to make the production of N-goods profitable, and that in the bad state there is a critical mass of insolvencies so that lenders will be bailed out. ${ }^{65}$ Next, we investigate when it is that currency mismatch generates price sequences that satisfy (10).

Equilibria. In the two economies we have considered investment is given by $I_{t}=m_{t} \frac{w_{t}}{p_{t}}$ and and cash flow equals the representative manager's wage: $w_{t}=\left(1-\beta_{t}\right) p_{t} q_{t}$, where $\beta_{t}$

\footnotetext{
${ }^{65}$ For a derivation of this result see Schneider and Tornell (2003).
} 
equals $\beta$ under solvency and $\mu_{w}$ under insolvency. Thus, the market clearing condition (7) implies that in any equilibrium

$$
I_{t}=\phi_{t} q_{t}, \quad \phi_{t}=\left[1-\beta_{t}\right] m_{t},
$$

where the investment multiplier $m_{t}$ can take the value $m^{s}$ or $m^{r}$. Combining (11) with (4) and (5) we have that in a symmetric equilibrium N-output, prices and T-output evolve according to

$$
\begin{aligned}
q_{t} & =\theta \phi_{t-1} q_{t-1} \\
p_{t} & =\alpha\left[q_{t}\left(1-\phi_{t}\right)\right]^{\alpha-1} \\
y_{t} & =\left[q_{t}\left(1-\phi_{t}\right)\right]^{\alpha}=\frac{1-\phi_{t}}{\alpha} p_{t} q_{t}
\end{aligned}
$$

In a non-liberalized economy the share of N-output that the N-sector commands for investment purposes is $\phi^{s}=\frac{1-\beta}{1-h \delta}$ during every period. Thus, there exists an equilibrium in such an economy if and only if: (i) the degree of contract enforceability satisfies $h<\bar{h}=\beta \delta^{-1}$, so that $\phi_{t}$ is less than one; and (ii) N-sector's productivity satisfies $\theta>\underline{\theta}=\left[\delta \beta\left(\phi^{s}\right)^{\alpha-1}\right]^{-1 / \alpha}$, so that the production of N-goods has a positive net present value $\frac{\beta \theta p_{t+1}}{p_{t}} \geq \delta^{-1}$.

In a liberalized economy there are two equilibria. The safe one we have just characterized, where agents choose not to issue T-debt. There is also a risky equilibrium that is composed of lucky paths which are punctuated by crises. Along a lucky path of this equilibrium all debt is denominated in T-goods and lenders will be bailed out in the next period if a majority of firms goes bust. Since the debt burden is not indexed to $p_{t}$, there are two market clearing prices. At the high price firms are solvent and their cash flow is $[1-\beta] \bar{p}_{t} q_{t}$. Thus, $\phi_{t}=(1-\beta) m^{r}$. However, at the low price N-firms are insolvent and their cash flow is only $\mu_{w} \underline{p}_{t} q_{t}$. Moreover, it can be shown that when $p_{t}=\underline{p}_{t}$, leverage is too low for fragility to arise and the real exchange rate to take on two values at $t+1$. Thus, at the time of the crisis agents find optimal to issue N-debt and the investment share is $\phi_{t}=\mu_{w} m^{s}$.

Resumption of risk taking takes place in the period after the crisis. Therefore, the path 
of N-sector investment is

$$
I_{t}=\phi_{t} q_{t}, \quad \phi_{t}= \begin{cases}\phi^{l}=\frac{1-\beta}{1-u^{-1} h \delta} & \text { if } p_{t}=\bar{p}_{t+1} \\ \phi^{c}=\frac{\mu_{w}}{1-h \delta} & \text { if } p_{t}=\underline{p}_{t+1}\end{cases}
$$

The sequence $\left\{q_{t}, p_{t}, y_{t}\right\}$ is then determined by using (13) to replace $\phi_{t}$ in (12a)-(12c). One can show that if crises are rare events there are thresholds for the degree of contract enforceability and for N-sector's productivity, such that if $h \in(\underline{h}, \bar{h})$ and $\theta \in(\underline{\theta}, \bar{\theta})$ returns satisfy (10), and thus a risky equilibrium exists. Notice that $h<\bar{h}$ and $\theta>\underline{\theta}$ ensure that when crises are rare events, investment is profitable. Meanwhile, $\theta<\bar{\theta}$ and $h>\underline{h}$ ensure that firms with T-debt go bust in the bad state, and that the fall in cash flow is translated into a large fall in credit and $\mathrm{N}$-investment, so that the fall in prices is validated. This establishes the second result.

Result 2. Financial liberalization increases investment in the financially constrained sector, but only if it makes the economy financially fragile and agents find it profitable to take on credit risk. This occurs only if the degree of contract enforceability satisfies $h \in(\underline{h}, \bar{h})$.

Notice that no exogenous shocks are necessary for crises, a shift in expectations is sufficient. A crisis can occur whenever firms expect that others will not undertake credit risk, so that there is a reversion to the safe equilibrium. The key to having multiple market clearing prices is that part of the N-sector's demand comes from the N-sector itself. Thus, when the price falls below a cutoff level and N-firms go bust, the investment share of the N-sector falls (from $\phi^{l}$ to $\phi^{c}$ ). This, in turn, reduces the demand for N-goods, validating the fall in the price.

We emphasize that the interaction of contract enforceability problems and systemic guarantees creates the fragility required for self-fulfilling crises. If there were no guarantees, agents would not be willing to take on credit risk to claim the implicit subsidy, and currency mismatch would not arise. Costly enforceability of contracts would still imply that the N-sector can grow only gradually and balance sheet effects would play a role during the 
lending boom. However, there would be no endogenous force that makes a boom end in a crisis. Alternatively, if there were only guarantees but no enforceability problems, then neither borrowing constraints nor balance sheet effects would arise. Thus, N-sector investment would not depend on its cash flow.

GDP Growth and Financial Fragility. We are now ready to rationalize the link between growth and fragility. Since N-goods are intermediate inputs, while T-goods are final consumption goods, gross domestic product equals the value of N-sector investment plus T-output: $g d p_{t}=p_{t} I_{t}+y_{t}$. It then follows from (11)-(12c) that

$$
g d p_{t}=y_{t}+p_{t} \phi_{t} q_{t}=q_{t}^{\alpha} Z\left(\phi_{t}\right)=y_{t} \frac{Z\left(\phi_{t}\right)}{\left[1-\phi_{t}\right]}, \quad Z\left(\phi_{t}\right)=\frac{1-[1-\alpha] \phi_{t}}{\left[1-\phi_{t}\right]^{1-\alpha}}
$$

As we can see, the key determinants of the evolution of GDP are the technological coefficient in T-production $\left(a_{t}\right)$ and the share of N-output invested by the N-sector $\left(\phi_{t}\right)$. In order to isolate the effects of financial liberalization, we have set $a_{t}$ to one.

In a non-liberalized economy the investment share $\phi_{t}$ is constant and equal to $\phi^{s}$. Thus, GDP and T-output grow at a common rate

$$
1+\gamma^{N L}:=\frac{g d p_{t}}{g d p_{t-1}}=\frac{y_{t}}{y_{t-1}}=\left(\theta \phi^{s}\right)^{\alpha}
$$

Absent technological progress in the T-sector, N-sector growth is the force driving growth in both sectors. As the N-sector expands, N-goods become more abundant and cheaper allowing the T-sector to expand production. This expansion is possible if and only if Nsector productivity $(\theta)$ and the N-investment share $\left(\phi^{s}\right)$ are high enough, so that credit and N-output can grow over time: $\frac{B_{t}}{B_{t-1}}=\frac{q_{t}}{q_{t-1}}=\theta \phi^{s}>1$. $^{66}$

A liberalized economy goes through a succession of lucky paths punctuated by crisis episodes. An economy is on a lucky path at time $t$ if there was no crisis either at $t-1$ or

\footnotetext{
${ }^{66}$ The mechanism by which higher growth in the $\mathrm{N}$-sector induces higher growth in the T-sector is the decline in the relative price of $\mathrm{N}$-goods that takes place in a growing economy $\frac{p_{t+1}}{p_{t}}=\left[\theta \phi^{s}\right]^{\alpha-1}$. If there were technological progress in the T-sector, there would be a Balassa-Samuelson effect and the real exchange rate would appreciate over time.
} 
at $t$. Since along a lucky path the investment share equals $\phi^{l},(14)$ implies that the common growth rate of GDP and T-output is $1+\gamma^{l}=\left(\theta \phi^{l}\right)^{\alpha}$. A comparison of $\gamma^{l}$ and (15) reveals that as long as a crisis does not occur, growth in a liberalized economy is greater than in a non-liberalized one. In the presence of systemic guarantees, credit risk allows financially constrained N-firms to borrow and invest more than in a non-liberalized economy $\left(\phi^{l}>\phi^{s}\right)$. Since there are sectorial linkages $(\alpha>0)$, this increase in the N-sector's investment share benefits both the T- and the N-sectors.

Because self-fulfilling crises occur with probability $1-u$, and during a crisis the investment share falls from $\phi^{l}$ to $\phi^{c}<\phi^{s}$, the fact that $\gamma^{l}>\gamma^{N L}$ does not imply that financial liberalization leads to higher mean GDP growth. The reduction in the investment share comes about through two channels: (i) N-sector firms go bust and their cash flow collapses (captured by $\frac{\mu_{w}}{1-\beta}$ ); and (ii) leverage falls because firms cannot take on credit risk (indexed by $\left.\frac{1-h \delta}{1-h \delta u^{-1}}\right)$. It follows from (14) that in a crisis episode that lasts two periods, the mean crisis growth rate is $1+\gamma^{c r}=\theta^{\alpha}\left(\phi^{l} \phi^{c}\right)^{\frac{\alpha}{2}}$. As we can see variations in GDP growth generated by real exchange rate changes at $\tau$ and $\tau+1$ cancel out. Thus, the average loss in GDP growth stems only from the fall in the N-sector's average investment share.

A liberalized economy experiences several crises over time. Therefore, to see whether financial liberalization will increase long-run growth, we compute the limit distribution of GDP's growth rate. Using the expressions for $\gamma^{l}$ and $\gamma^{c r}$, it follows that over the long run the mean compounded growth rate of GDP in a liberalized economy is ${ }^{67}$

$$
E\left(1+\gamma^{L E}\right)=\left(1+\gamma^{l}\right)^{\omega}\left(1+\gamma^{c r}\right)^{1-\omega}=\theta^{\alpha}\left(\phi^{l}\right)^{\alpha \omega}\left(\phi^{l} \phi^{c}\right)^{\alpha \frac{1-\omega}{2}}, \quad \text { where } \omega=\frac{u}{2-u}
$$

Notice that $\omega$ is the proportion of time that the economy is on a lucky path over the long-run. A comparison of long run GDP growth rates in (15) and (16) reveals that:

Result 3. Average long-run GDP growth is greater in a liberalized economy than in a nonliberalized one provided contract enforceability problems are severe, but not too severe

\footnotetext{
${ }^{67}$ For the computation of the limit distribution see Ranciere, et.al. (2003).
} 
$\left(h \in\left(h^{*}, h^{* *}\right)\right)$, and financial distress during crises is not too large $\left(\mu_{w}>\underline{\mu_{w}}\right)$.

The relationship between financial liberalization and growth is not straightforward because an increase in the probability of crisis $(1-u)$ has ambiguous effects on long-run growth. One the one hand, a greater $1-u$ increases investment and growth along the lucky path by increasing the subsidy implicit in the guarantee and allowing N-sector firms to be more leveraged. On the other hand, a greater $1-u$ makes crises more frequent. The degree of contract enforceability $h$ plays a key role. If we increase $1-u$, the growth enhancing effect of more investment dominates the growth reducing effect of more frequent crises when $h$ is large enough. This is because a large $h$ increases firms' leverage and allows them to reap the benefits of risk-taking. However, $h$ cannot be arbitrarily large to ensure the existence of an equilibrium. If $h$ were very large, borrowing constraints would not arise (by (9)), or there would not be market clearing, as $\phi^{l}>1$ (by (13)). ${ }^{68}$

The central role played by the requirement that " $h$ must be low, but not too low" underlies the importance of the country sample over which the empirical link between liberalization, and growth exists. The above result implies that among the set of countries where contract enforceability problems are severe, but not too severe, financial liberalization may lead to higher growth even if we control for trade liberalization. This prediction establishes a causal link from liberalization to GDP growth in the regressions of Section 2.

Credit Growth. Here we show that economies that have followed growth-enhancing risky credit paths are identified by a negatively skewed distribution of credit growth. Since in the model N-firms use only N-inputs, the appropriate measure of real credit is $\tilde{b}_{t}=\left(b_{t}+b_{t}^{n}\right) / p_{t}$. It follows from (8) and (9) that in a risky and a safe economy real credit is given, respectively, by

$$
\tilde{b}_{t}^{L E}=\left\{\begin{array}{ll}
{\left[\phi^{l}-(1-\beta)\right] q_{t}} & \text { if } \pi\left(p_{t}\right) \geq 0 \\
{\left[\phi^{c}-\mu_{w}\right] q_{t}} & \text { if } \pi\left(p_{t}\right)<0
\end{array} \quad \tilde{b}_{t}^{N L}=\left[\phi^{s}-(1-\beta)\right] q_{t}\right.
$$

\footnotetext{
${ }^{68}$ Higher long-run growth comes at the cost of a higher incidence of crises. A natural question is, thus, whether higher growth is associated with higher social welfare. Ranciere et.al. (2003) show that if T-sector agents have access to complete capital markets, so that they can hedge real exchange rate risk, then welfare in a risky equilibrium is greater than in a safe equilibrium provided enforceability problems are severe enough.
} 
In a safe non-liberalized economy credit follows a smooth path, while in a risky liberalized economy it follows a bumpy path. Using (12a), we have that in the latter the compounded growth rate of credit is $\zeta^{l}=\log \left(\theta \phi^{l}\right)$ along a lucky path, $\zeta^{c}=\log \left(\theta \phi^{l} u \frac{\mu_{w}}{1-\beta} \frac{1-h \delta u^{-1}}{1-h \delta}\right)$ during a crisis and $\zeta^{p}=\log \left(\theta \phi^{l} \frac{1}{u}\right)$ in the post-crisis period.

When skewness is negative, the good outcomes in the distribution lie closer to the mean than the bad outcomes. We find this credit pattern in the risky equilibrium because N-firms face endogenous borrowing constraints, so N-sector credit is constrained by cash flow. Along the lucky path -in which no crises occur- cash flow accumulates gradually, and credit can grow only gradually. In contrast, when a crisis erupts there are widespread bankruptcies and cash flow collapses. Thus, credit growth falls sharply $\left(\zeta^{c}<\zeta^{l}\right)$. In the wake of a crisis credit growth rebounds before returning to its lucky level $\left(\zeta^{p}>\zeta^{l}\right)$. As long as crises are rare events, the credit growth rates during the post-crisis period and the lucky path are very close $\left(\zeta^{p}-\zeta^{l}\right)=\log \left(u^{-1}\right)$. Since falls and rebounds occur with the same frequency, the distribution of credit growth is characterized by negative outliers in a long enough sample. That is

Result 4. In a risky liberalized economy the limit distribution of credit growth has negative skewness. Meanwhile, in a non-liberalized economy credit growth has a smooth path with zero skewness.

To link this result to our empirical findings recall that a risky equilibrium exists only if enforceability problems are severe but not too severe, conditions which we find in MECs. Thus, the first implication of this result is that financial liberalization may lead to bumpiness of credit growth across MECs. Since negative skewness of credit growth implies the adoption of credit risk, which eases financial constraints and leads to an increase in mean GDP growth (per result 3), the second implication is that negative skewness is an appropriate RHS variable in the growth regressions we estimate.

Notice that if enforceability problems were either not severe or too severe, there would be no endogenous force that would make credit growth negatively skewed to begin with. Thus, the link between negative skewness and growth would not exist. This is why skewness is 
statistically significantly in all growth regressions, even if we do not condition on the sample of countries.

In the model, credit growth exhibits more variance in the liberalized economy. Empirically, however, variance is not a good means of identifying economies that have followed growth-enhancing risky credit paths that lead to infrequent crises. High variance may also reflect high frequency shocks, which might be exogenous or might be self-inflicted by, for instance, bad economic policy. To generate high variance in both the safe and the risky equilibria, one could include in the model high frequency exogenous shocks that do not lead to crises. Such shocks would increase the variance of credit growth in both economies, but would not increase mean GDP growth. The two equilibria would still be distinguished by negative skewness of credit growth, because only the risky equilibrium would be crisis-prone.

The N-to-T Output Ratio. We have captured the sectorial asymmetry in financing opportunities prevalent in MECs by assuming that T-production is not affected by financial constraints, while the N-sector faces contract enforceability problems. This sectorial asymmetry generates two predictions about the behavior of the N-to-T output ratio $(\mathrm{N} / \mathrm{T})$ that help us identify the mechanism that links liberalization, fragility and growth in MECs.

Since the N-sector is more financially constrained than the T-sector, the first prediction is that along any equilibrium path $\mathrm{N} / \mathrm{T}$ is positively correlated with domestic credit. To derive the second prediction note that it follows from (12a)-(12c) that in a symmetric equilibrium $\mathrm{N} / \mathrm{T}$ is given by

$$
\frac{N_{t}}{T_{t}} \equiv \frac{p_{t} q_{t}}{y_{t}}=\frac{p_{t} q_{t}}{\frac{1-\phi_{t}}{\alpha} p_{t} q_{t}}=\frac{\alpha}{1-\phi_{t}}
$$

Investment equations (8) and (9) imply that when there is a shift from a non-liberalized to a liberalized economy the N-to-T output ratio increases from $\frac{\alpha}{1-\phi^{s}}$ to $\frac{\alpha}{1-\phi^{l}}$. This reflects the fact that financial liberalization eases financial constraints and allows the N-sector to command a greater share of N-inputs. ${ }^{69}$

If a crisis occurs at some date, say $\tau$, there is a fire-sale: there is a steep real exchange

\footnotetext{
${ }^{69}$ We have set $a_{t}$ to a constant. However, one can verify that an increase in $a_{t}$ following trade liberalization reduces $\mathrm{N} / \mathrm{T}$.
} 
rate depreciation, and since there is currency mismatch, all $\mathrm{N}$-firms default. As a result, the investment share falls from $\phi^{l}$ to $\phi^{c}$. The price of N-goods must fall to allow the T-sector to absorb a greater share of $\mathrm{N}$-output, which is predetermined by $\tau-1$ investment. As we can see in (18) N/T falls from $\frac{\alpha}{1-\phi^{l}}$ to $\frac{\alpha}{1-\phi^{c}}$. Thus,

Result 5. Across MECs, the N-to-T output ratio: (i) responds positively to financial liberalization and negatively to crises; and (ii) is positively correlated with credit growth.

Both of these implications of sectorial asymmetries are consistent with our empirical findings in Section 3. Furthermore, sectorial asymmetries are key to explaining several features of the boom-bust cycles experienced by many MECs, as well as Mexico's less than stellar growth and recent export slowdown. 


\section{APpendix B}

\section{Construction of Indexes, Data Sources, and Robustness Analysis}

Here we explain how we construct our liberalization indexes and the N-to-T output ratio, describe the data sets we used, and present results of some robustness tests.

\section{Liberalization Indexes}

Our de facto trade and financial liberalization indexes indicate the year when a given country liberalized. We construct the indexes by looking for trend breaks in trade and financial flows. We identify trend breaks by applying the CUSUM test of Brown and others (1975) to the time trend of the data. This method tests for parameter stability based on the cumulative sum of recursive residuals. ${ }^{70}$

A MEC is trade liberalized (TL) at year $t$ if its trade-to-GDP ratio either has a trend break at or before $t$ or has exceeded 30 percent at or before $t$. The 30 percent criterion identifies countries where trade was liberalized at the beginning of our sample (1980) or where the increase in trade flows did not take place from one year to the next, but instead took place over a few years. ${ }^{71}$

To determine the date of financial liberalization, we consider net cumulative capital inflows $(K I) .{ }^{72}$ A country is financially liberalized (FL) at year $t$ if $K I$ has a trend break at or before $t$ and there is at least one year with a KI-to-GDP ratio greater than 5 percent at or before $t$, or if its KI-to-GDP ratio is greater than 10 percent at or before $t$, or if the country is associated with the European Union. The 5 and 10 percent thresholds reduce the possibility of false liberalization and false nonliberalization signals, respectively. Table B1 lists the liberalization dates.

In order to determine the trend breaks, we regress each $K I$ series on a constant and a time trend. The CUSUM test is based on the cumulative sum of residuals of this regression. Figure B1 plots this cumulative sum together with the 5 percent critical values for Mexico's KI series. The test signals parameter instability of the time trend if the cumulative sum exits the area between the two critical lines. The test is based on the following statistic:

$$
W_{t}=\sum_{r=k+1}^{t} w_{r} / s, \text { for } t=k+1, \ldots ., T,
$$

where $w_{r}$ is the recursive residual and $s$ is the standard error of the regression fitted to all T-sample points. If the coefficient on the time trend remains constant from period to period, $E\left(W_{t}\right)=0$. But if it changes, $W_{t}$

\footnotetext{
${ }^{70}$ All HECs have liberalized trade and financial markets through the whole sample period.

${ }^{71}$ We compute the trade-to-GDP ratio as the ratio of exports plus imports over GDP, using data from the World Development Indicators of the World Bank.

${ }^{72}$ We compute cumulative net capital inflows sent by nonresidents since 1980. Capital inflows include FDI, portfolio flows, and bank flows. The data series are from the International Monetary Fund's International Financial Statistics, lines 78BUDZF,
} 
will tend to diverge from the zero mean value line. The significance of any departure from the zero line is assessed by reference to a pair of 5 percent significance lines. The distance between them increases with $t$. The 5 percent significance lines are found by connecting the points $k \pm 0.948(T-k)^{1 / 2}$ and $T \pm 3 \times 0.948(T$ $-k)^{1 / 2}$. A crossing of the critical lines by $W_{t}$ signals coefficient instability. ${ }^{73}$

When the cumulative sum of residuals starts to deviate from zero, it may take a few years until this deviation becomes statistically significant. To account for the delay problem, we choose the year in which the cumulative sum of residuals deviates from zero, provided that it eventually crosses the 5 percent significance level. In the case of Mexico, parameter instability begins in the fourth quarter of 1989 and becomes statistically significant after the fourth quarter of 1991.

Three comments are in order. First, our TL and FL indexes do not allow for policy reversals: once a country liberalizes, it never becomes closed thereafter. This means that our indexes do not capture some policy reversals that might have occurred in the latter part of the 1990s. Since our sample period is 1980-99, we consider our approach to be the correct one for analyzing the effects of liberalization on longrun growth and financial fragility. ${ }^{74}$ Second, in comparing different indexes it is convenient to distinguish liberalization from openness indexes. The former identify the dates of financial liberalization, whereas the latter measure the amount of capital flows that a country receives over a certain period. For instance, Bekaert, Harvey, and Lundblad (2001) and Kaminski and Schmukler (2002) consider liberalization indexes as we do, whereas Kraay (1998), Lane and Milesi-Ferretti (2002), and Edison and others (2002) consider openness indexes. Finally, the country-years identified as financially liberalized by our index, as well as the other liberalization indexes, do not necessarily coincide with "good times," because they include both boom and bust country-years. Therefore they are not subject to the criticism that liberalized country-years coincide with good times. The liberalization dates are reported in table B1.

78BGDZF, and 78BEDZ. For some countries not all three series are available for all years. In that case we use inflows to the banking system only, a measure that is available for all country-years.

${ }^{73}$ The underlying assumption is that the time series is trend stationary before the structural break. This is confirmed for the case of Mexico by unit root tests. The unit root tests are estimated with a constant, a time trend, and a number of lags (2) determined by the SIC criterion. Before liberalization the series is trend stationary. Including the post liberalization period, it has a unit root and is difference stationary.

${ }^{74}$ If, after liberalization, a country suffers a sharp reversal in capital flows (such as in a financial crisis), it might exhibit a second breakpoint. In our sample, however, this possibility is not present: the trend breaks due to crises are never large enough to show up in significant CUSUM test statistics. 
Table B1. Dates of Financial and Trade Liberalization and Sectors Used in N-to-T Output Ratios ${ }^{\mathrm{a}}$

\begin{tabular}{lcccc}
\hline & & \multicolumn{2}{c}{$\begin{array}{c}\text { Sectors designated tradable and } \\
\text { nontradable for regressions including } \\
\text { the N-to-T output ratio }\end{array}$} \\
\cline { 3 - 5 } Country & Date of financial & $\begin{array}{c}\text { bate of trade } \\
\text { liberalization }\end{array}$ & $\begin{array}{c}\text { Based on export } \\
\text { liberalization }\end{array}$ & $\begin{array}{c}\text { Based on real } \\
\text { exchange rates }\end{array}$ \\
\hline Argentina & 1991 & 1986 & $\mathrm{C}, \mathrm{M}$ & $\mathrm{C}, \mathrm{M}$ \\
Bangladesh & Never & Never & $\mathrm{S}, \mathrm{M}$ & $\mathrm{S}, \mathrm{M}$ \\
Belgium & Always & Always & $\mathrm{C}, \mathrm{M}$ & $\mathrm{C}, \mathrm{M}$ \\
Brazil & 1992 & 1988 & $\mathrm{~S}, \mathrm{M}$ & $\mathrm{S}, \mathrm{M}$ \\
Chile & Always & Always & $\mathrm{C}, \mathrm{M}$ & $\mathrm{C}, \mathrm{M}$ \\
Colombia & 1991 & 1992 & $\mathrm{~S}, \mathrm{M}$ & $\mathrm{S}, \mathrm{M}$ \\
Egypt & Always & 1991 & $\mathrm{~S}, \mathrm{M}$ & $\mathrm{S}, \mathrm{M}$ \\
Greece & Always & 1986 & $\mathrm{~S}, \mathrm{M}$ & $\mathrm{S}, \mathrm{M}$ \\
Hong Kong & Always & Always & $\mathrm{NA}$ & $\mathrm{NA}$ \\
Hungary & 1994 & 1994 & $\mathrm{~S}, \mathrm{M}$ & $\mathrm{S}, \mathrm{M}$ \\
India & Never & 1994 & $\mathrm{~S}, \mathrm{M}$ & $\mathrm{S}, \mathrm{M}$ \\
Indonesia & 1989 & 1987 & $\mathrm{~S}, \mathrm{M}$ & $\mathrm{S}, \mathrm{M}$ \\
Ireland & Always & Always & $\mathrm{NA}$ & $\mathrm{NA}$ \\
Israel & 1990 & 1986 & $\mathrm{NA}$ & $\mathrm{NA}$ \\
Jordan & 1989 & Always & $\mathrm{S}, \mathrm{M}$ & $\mathrm{S}, \mathrm{M}$ \\
Korea & 1985 & Always & $\mathrm{C}, \mathrm{M}$ & $\mathrm{C}, \mathrm{M}$ \\
Malaysia & Always & Always & $\mathrm{C}, \mathrm{M}$ & $\mathrm{C}, \mathrm{M}$ \\
Mexico & 1989 & 1988 & $\mathrm{C}, \mathrm{M}$ & $\mathrm{C}, \mathrm{M}$ \\
Morocco & Never & 1986 & $\mathrm{~S}, \mathrm{M}$ & $\mathrm{S}, \mathrm{M}$ \\
Pakistan & Never & Never & $\mathrm{S}, \mathrm{M}$ & $\mathrm{S}, \mathrm{M}$ \\
Peru & 1992 & 1987 & $\mathrm{M}, \mathrm{S}$ & $\mathrm{S}, \mathrm{M}$ \\
Philippines & 1989 & 1986 & $\mathrm{C}, \mathrm{M}$ & $\mathrm{C}, \mathrm{M}$ \\
Poland & Never & 1993 & $\mathrm{NA}$ & $\mathrm{S}, \mathrm{M}$ \\
Portugal & 1986 & 1986 & $\mathrm{C}, \mathrm{M}$ & $\mathrm{C}, \mathrm{M}$ \\
South Africa & 1994 & Never & $\mathrm{S}, \mathrm{M}$ & $\mathrm{S}, \mathrm{M}$ \\
Spain & Always & 1984 & $\mathrm{~S}, \mathrm{M}$ & $\mathrm{S}, \mathrm{M}$ \\
Sri Lanka & Never & 1989 & $\mathrm{~S}, \mathrm{M}$ & $\mathrm{S}, \mathrm{M}$ \\
Thailand & 1988 & 1986 & $\mathrm{C}, \mathrm{M}$ & $\mathrm{C}, \mathrm{M}$ \\
Tunisia & Never & Always & $\mathrm{M}, \mathrm{S}$ & $\mathrm{S}, \mathrm{M}$ \\
Turkey & Always & 1994 & $\mathrm{C}, \mathrm{S}$ & $\mathrm{C}, \mathrm{M}$ \\
Uruguay & 1989 & 1988 & $\mathrm{NA}$ & $\mathrm{NA}$ \\
Venezuela & Never & Never & $\mathrm{S}, \mathrm{M}$ & $\mathrm{S}, \mathrm{M}$ \\
Zimbabwe & Never & & $\mathrm{S}, \mathrm{M}$ \\
\hline
\end{tabular}

Source: Authors' calculations.

a. "Always" indicates that the country has been open at least since 1980; "Never" indicates that the country was closed at least until 1999.

b. The first of each pair is the sector designated as nontradable, and the second that designated as tradable; $\mathrm{C}$, construction; $\mathrm{M}$, manufacturing; $\mathrm{S}$, services.

c. The sample does not cover the period before 1993; the financial liberalization date is therefore set to 1989, which fits the dates of Kaminsky and Schmukler (2002) and Bekaert, Harvey, and Lundblad (2001).

\section{The N-to-T Output Ratio}

We construct the $\mathrm{N}$-to-T output ratio by proxying $\mathrm{N}$-sector and $\mathrm{T}$-sector production with data for construction, manufacturing, and services. In the text of the paper we use the sectoral exports-to-GDP ratio as the criterion for classifying the $\mathrm{N}$ - and T-sectors. Construction is never classified as a T-sector. Meanwhile the classification of services and manufacturing varies from country to country. Since the price 
of N-sector goods tracks international prices less closely than that of T-sector goods, we construct an alternative index in which we classify as nontradable the sectors in which the sectoral real exchange rate varies the most, and as tradable the sectors in which it varies the least. Table B1 reports both indexes. The correlation between them is 0.745 . Table $\mathrm{B} 2$ shows that the regression results reported in table 4 are robust to the choice of index.

Table B2. Regressions Testing for Sectoral Asymmetries ${ }^{a}$

\begin{tabular}{|c|c|c|c|}
\hline Independent variable & B2-1 & B2-2 & $B 2-3$ \\
\hline \multirow[t]{2}{*}{ Financial liberalization } & $1.129 * *$ & $0.979^{* *}$ & $0.996 * *$ \\
\hline & $(0.142)$ & $(0.149)$ & $(0.141)$ \\
\hline \multirow[t]{2}{*}{ Trade liberalization } & $-0.747 * *$ & $-0.5618 * *$ & $-0.772 * *$ \\
\hline & $(0.191)$ & $(0.198)$ & $(0.203)$ \\
\hline \multirow[t]{2}{*}{ Credit } & & $0.479^{* *}$ & $0.439 * *$ \\
\hline & & $(0.205)$ & $(0.192)$ \\
\hline Rate of real depreciation & & & $\begin{array}{l}2.260^{*} \\
(1.374)\end{array}$ \\
\hline Crisis year dummy & $\begin{array}{c}-0.021^{*} \\
(0.014)\end{array}$ & $\begin{array}{l}-0.019 * \\
(0.013)\end{array}$ & $\begin{array}{c}0.003 \\
(0.012)\end{array}$ \\
\hline Crisis year +1 & $\begin{array}{c}-2.444 * * \\
(0.144)\end{array}$ & $\begin{array}{c}-2.134^{* *} \\
(0.184)\end{array}$ & $\begin{array}{c}-2.240 * * \\
(0.178)\end{array}$ \\
\hline Crisis year +2 & $\begin{array}{l}0.207^{*} \\
(0.128)\end{array}$ & $\begin{array}{c}0.447^{* *} \\
(0.155)\end{array}$ & $\begin{array}{c}0.375^{* *} \\
(0.147)\end{array}$ \\
\hline Crisis year +3 & $\begin{array}{c}-0.784 * * \\
(0.128)\end{array}$ & $\begin{array}{c}-0.648^{* *} \\
(0.130)\end{array}$ & $\begin{array}{c}-0.690 * * \\
(0.122)\end{array}$ \\
\hline Crisis year +4 & $\begin{array}{c}-0.478^{* *} \\
(0.194)\end{array}$ & $\begin{array}{l}-0.236 \\
(0.204)\end{array}$ & $\begin{array}{c}0.341^{*} \\
(0.194)\end{array}$ \\
\hline Crisis year +5 & $\begin{array}{c}0.856^{* *} \\
(0.184)\end{array}$ & $\begin{array}{c}0.827^{* *} \\
(0.163)\end{array}$ & $\begin{array}{c}0.911 * * \\
(0.155)\end{array}$ \\
\hline \multicolumn{4}{|l|}{ Summary statistics: } \\
\hline Adjusted $R^{2}$ & 0.691 & 0.728 & 0.745 \\
\hline No. of observations & 443 & 426 & 371 \\
\hline
\end{tabular}




\section{Robustness Tests}

Table B3 shows results of tests of the robustness of the benchmark regressions in columns 1-3 and 3-2 in tables 1 and 3 , respectively.

Table B3. Robustness Tests

\begin{tabular}{|c|c|c|c|c|c|}
\hline Independent variable & $B 3-1^{a}$ & $B 3-2^{\mathrm{b}}$ & $B 3-3^{c}$ & $B 3-4^{\mathrm{d}}$ & $B 3-5^{\mathrm{e}}$ \\
\hline \multicolumn{6}{|c|}{ Regressions of growth on liberalization ${ }^{f}$} \\
\hline Financial liberalization & $\begin{array}{c}2.980^{* *} \\
(0.363)\end{array}$ & $\begin{array}{c}3.036^{* *} \\
(0.668)\end{array}$ & $\begin{array}{l}1.571^{* *} \\
(0.181)\end{array}$ & $\begin{array}{c}2.686^{* *} \\
(0.132)\end{array}$ & $\begin{array}{c}2.467 * * \\
(0.119)\end{array}$ \\
\hline \multicolumn{6}{|l|}{ Summary statistics: } \\
\hline Adjusted $R^{2}$ & 0.615 & 0.615 & 0.953 & 0.547 & 0.568 \\
\hline No. of observations & 423 & 423 & 460 & 450 & 450 \\
\hline \multicolumn{6}{|c|}{ Regressions of growth on bumpiness measures ${ }^{\mathrm{g}}$} \\
\hline $\begin{array}{l}\text { Mean of real credit } \\
\text { growth rate }\end{array}$ & $\begin{array}{c}0.051^{* *} \\
(0.010)\end{array}$ & $\begin{array}{l}0.130^{* *} \\
(0.019)\end{array}$ & $\begin{array}{l}0.065^{* *} \\
(0.009)\end{array}$ & $\begin{array}{c}0.123 * * \\
(0.010)\end{array}$ & $\begin{array}{l}0.127 * * \\
(0.009)\end{array}$ \\
\hline $\begin{array}{l}\text { Standard deviation of } \\
\text { real credit growth rate }\end{array}$ & $\begin{array}{c}-0.027^{* *} \\
(0.006)\end{array}$ & $\begin{array}{c}-0.030^{* *} \\
(0.007)\end{array}$ & $\begin{array}{l}-0.001 \\
(0.003)\end{array}$ & $\begin{array}{c}-0.027^{* *} \\
(0.004)\end{array}$ & $\begin{array}{c}-0.032 * * \\
(0.004)\end{array}$ \\
\hline $\begin{array}{l}\text { Negative skewness of } \\
\text { real credit growth rate }\end{array}$ & $\begin{array}{c}0.354^{* *} \\
(0.071)\end{array}$ & $\begin{array}{c}0.212^{* *} \\
(0.097)\end{array}$ & $\begin{array}{l}0.066^{* *} \\
(0.025)\end{array}$ & $\begin{array}{c}0.207 * * \\
(0.036)\end{array}$ & $\begin{array}{l}0.216^{* *} \\
(0.037)\end{array}$ \\
\hline \multicolumn{6}{|l|}{ Summary statistics: } \\
\hline Adjusted $R^{2}$ & 0.617 & 0.619 & 0.901 & 0.562 & 0.630 \\
\hline No. of observations & 383 & 383 & 424 & 414 & 414 \\
\hline
\end{tabular}

Source: Authors' regressions.

a. Instrumental variables regression estimated by two-stage least squares, using the legal origin index of La Porta and others (1999) as an instrument. All regressions include the combined MEC and HEC sample of countries. Standard errors are reported in parentheses. ** indicates significance at the 5 percent level.

b. Instrumental variables regression estimated by two-stage least squares, using lagged values as instruments.

c. Regression estimated by the generalized least squares methods allowing for fixed effects.

d. Regression estimated with a common intercept, but leaving out China.

e. Regression estimated with a common intercept, but leaving out Ireland.

f. Regressions correspond to that reported in column 1-3 in the text.

g. Regressions correspond to that reported in column 3-2 in the text. 


\section{References}

Aghion, Philippe, Philippe Bachetta, and Abhijit Banerjee (2000), "Capital Markets and the Instability of Open Economies," WP, Study Center Gerzensee.

Bekaert, G. and Campbell Harvey, and R. Lundblad, (2001), “Does Financial Liberalization Spur Growth,” NBER WP 8245.

Bernanke, Ben, Mark Gertler, and Simon Gilchrist (2000), "The Financial Accelerator in a Quantitative Business Cycle Framework," in Taylor and Woodford eds. Handbook of Macroeconomics, North Holland.

Betts, Caroline and Timothy Kehoe (2002), "Real Exchange Rate Movements and the Relative Price of Nontraded Goods," Federal Reserve Bank of Minneapolis, Staff Report.

Bordo, Michael and Barry Eichengreen (2002) "Crises Now and Then: What Lessons From the Last Era of Financial Globalization,” NBER WP 8716.

Burnside, Craig, Martin Eichenbaum, and Sergio Rebelo (2001), "Prospective Deficits and the Asian Currency Crisis," Journal of Political Economy, 109, 1155-97.

Caballero, Ricardo and Arvind Krishnamurthy (2001), "International and Domestic Collateral Constraints in a Model of Emerging Market Crises," Journal of Monetary Economics, 48, 513-48.

Calvo, Guillermo (1998), "Capital Flows and Capital Market Crises: The Simple Economics of Sudden Stops," Journal of Applied Economics, 1(1): 35-54.

Chang, Roberto and Andres Velasco (1998), "Financial Crises in Emerging Markets: A Canonical Model,” NBER working paper 6606.

Chari, A. and P. Henry (2002), “Capital Account Liberalization: Allocative Efficiency or Animal Spirits?” NBER WP 8908.

Chinn, Menzie D. and Kenneth M. Kletzter (2000), “International Capital Inflows, Domestic Financial Intermediation and Financial Crises under Imperfect Information,” NBER WP 7902.

Cole, Harold and Timothy Kehoe (2000), "Self-Fulfilling Debt Crises,” Review of Economic Studies, 67, 91-116.

Corsetti, Giancarlo, Paolo Pesenti, and Nouriel Roubini (1999), "Paper Tigers: A Model of the Asian Crisis," European Economic Review, 43, 1211-1236.

Cuevas A., M. Messmacher and A. Werner (2003), "Macroeconomic Synchronization between Mexico and its NAFTA Partners," mimeo.

Demirgüc-Kunt, Asli and Ross Levine (2001), "Financial Structure and Economic Growth: A Cross-Country Comparison of Banks, Markets, and Development," Cambridge, MA: MIT Press.

Dollar, David and Aart Kraay (2002), "Institutions, Trade and Growth," Carnegie Rochester Conference Series on Public Policy.

Edison, Hali J., Ross Levine, Luca Ricci, and Torsten Sloek (2002), “International Financial Integration and Growth,” Journal of International Money and Finance, 21, 749-76.

Edwards, S. (1998), “Openess, Productivity, and Growth: What Do We Really Know?” Economic Journal, 108, 383-398.

Engel, Charles (1999), “Accounting for U.S. Real Exchange Rates,” Journal of Political Economy, 107(3), 507-38.

Fatas, A. and I. Mihov (2002), “The Case for Restricting Fiscal Policy Discretion,” CEPR Discussion Paper No. 3277.

Frankel, J. and D. Romer (1999), “Does Trade Cause Growth?” American Economic Review, 89, 379-399.

Gourinchas, Pierre Olivier, Oscar Landerretche, and Rodrigo Valdes (2001), "Lending Booms: Latin America and the World," NBER WP 8249. 
Gourinchas, Pierre Olivier and Olivier Jeanne (2003), “The Elusive Gains from International Financial Integration,” NBER WP 9684.

Imbs, Jean (2002), "Why the Link Between Volatility and Growth is Both Positive and Negative," London School of Economics, mimeo.

Kaminski, Graciela and Carmen Reinhart (1999), "The Twin Crises: The Causes of Banking and Balance of Payments Problems," American Economic Review, 89, 473-500.

Kaminsky, Graciela and Sergio Schmukler (2002), "Short-Run Pain, Long-run Gain: The Effects of Financial Liberalization," World Bank Working Paper 2912.

Konrad, Kai A. (1992), “Risikoproduktivität,” Contemporary Studies in Economics, Springer, Heidelberg, Berlin.

Krugman, Paul (1999), "Balance Sheets, The Transfer Problem, and Financial Crises,” MIT mimeo.

La Porta, Rafael, Florencio Lopez-de-Silanes, Andrei Shleifer and Robert Vishny (1999), “The Quality of Government," Journal of Law, Economics and Organization; 15(1): 222-79.

Levine, Ross, Norman Loayza and Torsten Beck (2000), "Financial Intermediation and Growth: Causality and Causes," Journal of Monetary Economics, 46(1): 31-77.

Loayza, Norman and Romain Ranciere (2001), "Financial Development, Financial Fragility and Growth," NYU mimeo.

McKinnon, Ronald (1973), “Money and Capital in Economic Development,” Washington: Brookings Institution.

McKinnon, Ronald and Huw Pill (1999), "Exchange-Rate Regimes for Emerging Markets: Moral Hazard and International Overborrowing," Oxford Review of Economic Policy, 15, 19-38.

Newey, W. and K. West (1987), “A Simple, Positive Semi-Definite, Heteroskedasticity and Autocorrelation Consistent Covariance Matrix,” Econometrica, 55, 703-708.

Obstfeld, Maurice (1986), "Rational and Self-fulfilling Balance of Payments Crises," American Economic Review, 76, 72-81.

Obstfeld, Maurice (1994), “Risk Taking, Global Diversification and Growth,” American Economic Review.

Prasad E., K. Rogoff, S. Wei and A. Kose (2003), "Effect of Financial Globalization on Developing Countries: Some Empirical Evidence," IMF.

Rajan R. and L. Zingales (1998), “Financial Dependence and Growth,” American Economic Review, 88, 559-586.

Ramey, G. and V. Ramey (1995), “Cross Country Evidence on the Link Between Volatility and Growth,” American Economic Review, 85, 1138-1151.

Ranciere, Romain, Aaron Tornell and Frank Westermann (2003), “Crises and Growth: A Re-evaluation,” UCLA mimeo.

Sachs, Jeffrey, Aaron Tornell, and Andres Velasco (1996a), "Financial Crises in Emerging Markets: The Lessons From 1995," Brookings Papers on Economic Activity, 147-98.

Sachs, Jeffrey and Andrew Warner (1995), "Economic Reform and the Process of Global Integration,” Brookings Papers on Economic Activity, 1-118.

Schneider, Martin and Aaron Tornell (forthcoming), "Balance Sheet Effects, Bailout Guarantees and Financial Crises," Review of Economic Studies.

Silverman, B. W. (1986), "Density Estimation for Statistics and Data Analysis,” Chapman \& Hall.

Sinn, Hans-Werner (1986), "Risiko als Produktionsfaktor," Jahrbücher für Nationalökonomie and Statistik 201, pp. 557-571. 
Tirole, Jean (2002), Financial Crises, Liquidity, and the International Monetary System, Princeton University Press.

Tornell, Aaron and Andres Velasco (1992), "The Tragedy of the Commons and Economic Growth: Why Does Capital Flow From Poor to Rich Countries?” Journal of Political Economy.

Tornell, Aaron and Frank Westermann (2002), “Boom-Bust Cycles: Facts and Explanation,” IMF Staff Papers.

Tornell, Aaron and Frank Westermann (2003), “Credit Market Imperfections in Middle Income Countries,” NBER WP 9737. Veldkamp, Laura (2002), “Slow Boom, Sudden Crash,” INSEAD mimeo. 